\title{
SARS-CoV Regulates Immune Function-Related Gene Expressions in Human Monocytic Cells
}

\author{
Wan-Chung(Wan-Jiung) $\mathrm{Hu}^{1}$, Yu-Ting Yen ${ }^{1}$, Sher Singh ${ }^{3}{ }^{4}$, Chuan-Liang Kao ${ }^{2}$, Betty \\ A.Wu-Hsieh ${ }^{1 *}$ \\ * Corresponding author: bwh@ntu.edu.tw \\ 1. Graduate Institute of Immunology, National Taiwan University College of Medicine \\ 2. Department of Clinical Laboratory Sciences and Medical Biotechnology, National \\ Taiwan University College of Medicine \\ 3. NTU Center for Genomic Medicine, National Taiwan University Hospital \\ No.1 Jen-Ai Road, Section 1, Taipei 100, Taiwan ROC
}

Fax 886-2-2321-7921

Phone 886-2-2321-7510

4. Present address: Department of Life Sciences, National Taiwan Normal University, No.162, He-Ping East Road, Section 1, Taipei 106, Taiwan ROC 


\begin{abstract}
Background: Severe Acute Respiratory Syndrome (SARS) is characterized by acute respiratory distress (ARDS) and pulmonary fibrosis, and monocyte/macrophage is the key player in the pathogenesis of SARS.

Methods: In this study, we compared the transcriptional profiles of SARS coronavirus (SARS-CoV) infected monocytic cells against that infected by coronavirus 229E (CoV229E). Total RNA was extracted from infected DC-SIGN transfected monocytes (THP-1DC-SIGN) at 6 and $24 \mathrm{~h}$ after infection and the gene expression was profiled in oligonucleotide-based microarray.

Results: Analysis of immune-related gene expression profiles showed that at $24 \mathrm{~h}$ after SARS-CoV infection, (i) IFN- $\alpha / \beta$-inducible and cathepsin/proteosome genes were downregulated; (ii) the hypoxia/hyperoxia-related genes were up-regulated; and (iii) the TLR/TLR-signaling, cytokine/cytokine receptor-related, chemokine/chemokine receptorrelated, the lysosome-related, $\mathrm{MHC} /$ chaperon-related, and fibrosis-related genes were differentially regulated.

Conclusion: These results elucidate that monocyte/macrophage dysfunction and dysregulation of fibrosis-related genes are two important pathogenic events of SARS.
\end{abstract}




\section{Background}

During the months of November 2002 to July 2003, the outbreak of Severe Acute Respiratory Syndrome (SARS) greatly impacted the public health around the world. A total of 8096 cases and 774 deaths [1] were reported. About $20 \%$ of SARS patients developed acute respiratory distress syndrome (ARDS) [2]. Chest X-rays revealed bilateral diffuse consolidation in these patients [3]. Massive macrophage infiltration is a prominent feature in the lung sections of patients who died of SARS [4]. SARS-CoV infects human monocytes [5] and monocytic cells infected by SARS-CoV produce chemokines that attract the migration of neutrophils, macrophages and activated $\mathrm{T}$ lymphocytes [6]. Patients who recovered from SARS often suffered a sequel of pulmonary fibrosis [7] and macrophages play a role in fibroblast accumulation [8]. Thus, it is strongly indicated that immune response plays an important role in the pathogenesis of SARS and that monocyte/macrophage is the key player in the immunopathogenesis of SARS.

Microarray is a recently developed tool that is useful in revealing the host response to an infectious agent at the genomic level. The microarray methodology has been used to show immune cell gene expression profile after infections by Mycobacterium leprae, CMV, HIV, E. coli, Chlamydia pneumoniae, and influenza virus H5N1 [9-14]. The gene expression profile in the peripheral blood mononuclear cells of convalescent SARS patients has been reported in a microarray study [15]. The molecular signature and disease severity index thus identified are useful for the diagnosis and prognosis of SARS- 
$\mathrm{CoV}$ infection if another SARS outbreak should occur [15]. However, the expression of immune function-related genes in SARS-CoV-infected monocyte/macrophage has never been revealed

In the present study, oligo-microarray was used to profile the expression of immune function-related genes. We used DC-SIGN stably transfected monocytic THP-1 cells as targets to model the alveolar environment, as it has been shown that interstitial alveolar macrophages in the histologically normal adult lung tissue constitutively express DCSIGN [16]. The gene expression profile induced by SARS-CoV was compared to the human coronavirus 229E (CoV-229E), a group I coronavirus that causes mild common cold, of which the infectivity of DC-SIGN-transfected THP-1 cells is comparable to that of SARS-CoV [6]. Since SARS-CoV induced chemokine gene expression in monocytic

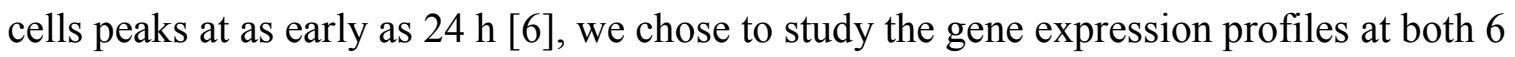
and $24 \mathrm{~h}$ after infection. The results of the present study showed that after SARS-CoV infection of monocytes, the expressions of (i) IFN- $\alpha / \beta$-inducible and cathepsin/proteosome genes were down-regulated; (ii) the hypoxia/hyperoxia-related gene were up-regulated; and (iii) the TLR/TLR-signaling, cytokine/cytokine receptorrelated, chemokine/chemokine receptor-related, the lysosome-related, $\mathrm{MHC} /$ chaperonrelated, and fibrosis-related genes were differentially regulated.

\section{Methods}

\section{Monocytic cell culture}


The THP-1 cell line human monocytic cell line THP-1 stably transfected with DC-SIGN (THP-1-DC-SIGN) was kindly provided by Dr. Vineet N. Kewal Ramani (Model Development Section, HIV Drug Resistance Program, National Cancer Institute, National Institute of Health). The cell line was maintained in RPMI1640 supplemented with 10\% heat-inactivated fetal bovine serum (FBS) in $5 \% \mathrm{CO} 2$ at $37^{\circ} \mathrm{C}$.

\section{Virus infection}

THP-1-DC-SIGN cells were seeded in $15 \mathrm{ml}$ culture tubes at a density of $1 \times 10^{6}$ cells $/ \mathrm{ml}$. Cells were left in medium or infected with SARS-CoV TW1 [17] or CoV-229E at 100fold $50 \%$ tissue culture infective doses $\left(\mathrm{TCID}_{50}\right.$, titered in Vero E6 or MRC-5 cells, respectively) and incubated for 6 or $24 \mathrm{~h}$. At different time points after infection, cells were harvested and culture supernatants were collected and stored at $-70^{\circ} \mathrm{C}$. For chip hybridization assay, cell pellets were resuspended in TRIzol. Experiments that required handling SARS-CoV were performed in the P3 facility in the National Taiwan University College of Medicine. All procedures were performed according to the Centers for Disease Control and Prevention P3 Biosafety Guidelines.

\section{RNA extraction}

Total RNA was extracted from un-infected, CoV-229E infected, and SARS-CoV infected THP-1-DC-SIGN cells. After chloroform was added to each tube, samples were centrifuged and RNA contents were isolated from the upper aqueous phase. Glycogen and iso-propanol were added to precipitate the total RNA. After wash by $75 \%$ ethanol, total RNA was spun down and stored in DEPC-water. The A260/A280 O.D. ratio of all 
RNA samples were $>1.800$ as determined by nanodrop-spectrophotometer (NanoDrop Technologies, Wilmington, DE, USA). Capillary RNA gel electrophoresis (Agilent Inc, Palo Alto, CA) was performed to ensure that the total RNA samples had clear $18 \mathrm{~S}$ and 28S ribosomal RNA bands.

\section{Chip hybridization}

Oligonucleotide-based microarrays, validated by the U.S. National Cancer Institute[18], were provided by Compugen (Jamesburg, NJ) and printed by an OmniGrid arrayer (San Carlos, CA). A total of 19,137 oligos was used in the microarrays. QIAgen (Valencia, CA) RNA clean-up column containing DNase was used to further purify RNA samples. Twenty $\mu \mathrm{g}$ of RNAs from SARS-CoV- and CoV-229E-infected DC-SIGN-THP-1 cells and $40 \mu \mathrm{g}$ of RNAs from uninfected controls were labeled with cyanine 3-dUTP(Cyt3) and cyanine 5-dUTP(Cyt5), respectively. The Cyt3 and Cyt5 labeled samples were then

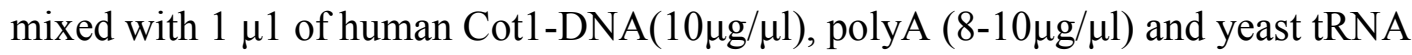
$(4 \mu \mathrm{g} / \mu \mathrm{l})$ each to block non-specific binding. The sample mixture was then denatured at $100^{\circ} \mathrm{C}$ for $1 \mathrm{~min}$. Twenty $\mu \mathrm{l}$ of $2 \mathrm{X}$ hybridization buffer ( $50 \%$ formamide, $10 \mathrm{X} \mathrm{SSC}$, and $0.2 \%$ SDS) was added onto each prehybridized slide. Hybridization was performed in a humid chamber in a water bath at $42^{\circ} \mathrm{C}$ overnight. Two arrays for both SARS-CoV and CoV-229E for each time-point were obtained.

\section{Image and Data analysis}

After hybridization, the slides were scanned on a GenePix 4000A scanner (Axon Instrument, Foster City, CA). The TIFF images were then analyzed by GenePix Pro 
software and GPR files were generated. Signal dots were aligned with the grid first. The signal dots that were too small were deleted. In the appearance of bubbles and severe scratches in the slide image, the signal dots were considered invalid. A PMT gain of red light $(635 \mathrm{~nm})$ intensity and green light $(532 \mathrm{~nm})$ intensity was adjusted according to the following principles: First, a general normalization method was applied to ensure that the ratio of total correct light intensity to green light intensity was equal to 1:1. Second, all the housekeeping gene-glyceraldehyde-3-phosphate dehydrogenease (GAPDH) dots were adjusted so they appear to be yellow, as GAPDH should not have been up- or downregulated. _Microarray chip hybridization results for SARS-CoV and CoV-229E at 24h time point are shown as Figure 1A and 1B, respectively. All the data were uploaded to the US National Cancer Institute Microarray Website for data processing, transformation, and annotation. The transformed numeral data, with gene annotations, were then downloaded from the above website. Genes were highlighted when the average expression ratios (Fold change) were $\geq 1.5$ ( $\geq 1.5$-fold up-regulation (boldface) or $\leq 0.67$ ( $\geq 1.5$-fold down-regulation ) (underlined boldface). When the intensity ratio was positive from one replicate and negative from the other replicate, the images from the GPR files were re-checked. If the dada were still inconsistent, they were excluded from further analysis. Heatmap of microarray results is shown. (Figure 1)

\section{Pathway network analysis}

Ingenuity pathway analysis software was used to identify specific up-regulated or downregulated gene-to-gene network at $24 \mathrm{~h}$ after SARS-CoV infection. Data including gene name and fold change levels were input into the software. Genes which are immune 
response related genes were selected in the pathway analysis. In this analysis, two major immunological pathway networks were identified including IL-8 centered network and proteasome-related gene network. (Figure 2)

\section{Results}

\section{The expressions of IFN $\alpha / \beta$ inducible genes are down-regulated}

IFN $\alpha / \beta$ is the first line of host defense against virus infection. The expressions of IFN $\alpha$ 14, and RNA activated protein kinase, an enzyme that phosphorylates EIF2 to inhibit cellular protein translation [19], were slightly up-regulated after CoV-229E infection at both $6 \mathrm{~h}$ and remained up-regulated at $24 \mathrm{~h}$, and IFN-inducible guanylate binding proteins (GIP2 and GIP3) and IFN-inducible myxovirus resistance1 (MX1) were moderately down-regulated at $24 \mathrm{~h}$ (Table 1) after infection. Interestingly, almost all interferonrelated genes were down-regulated by $>1.5$-fold in SARS-CoV infected monocytic cells at $6 \mathrm{~h}$ (Table 1). These genes included IFN-induced protein 35 (IFI 35), IFN-inducible G1Ps (GIP3 and GIP2), 2', 5' oligoadenylate synthetase 2 (2,5 OAS2), IFN-inducible myxovirus resistance1 (MX1), and IFN- $\alpha$-inducible protein 44 . At $24 \mathrm{~h}$ after SARS-CoV infection, more IFN-related genes were down-regulated and these IFN-related genes included IFN- $\alpha 14$, IFN-stimulated 3 gamma (ISGF3g), IFN-induced exonuclease, RNA activated protein kinase (eukaryotic translation initiation factor $2 \alpha$ kinase, EIF2AK), in addition to IFN-induced protein 35, G1Ps, 2,5 OAS2, MX1, and IFN- $\alpha$-inducible protein 44. It is worth noting that IFN-inducible GIP3, 2,5 OAS2, MX1, and IFN- $\alpha$-inducible 
protein 44 were down-regulated by $>2$-fold at both 6 and $24 \mathrm{~h}$ after SARS-CoV infection. These results indicate that while CoV-229E induces IFN $\alpha$ responses, SARS-CoV infection of macrophages not only does not induce IFN $\alpha / \beta$ response but also down regulate IFN-related genes.

\section{The expressions of Toll-like receptors and Toll-like receptor signaling molecules are differentially regulated}

Triggering Toll-like receptor-signaling pathway is important to the induction of innate immune responses [20]. CoV-229E infection induced up-regulation of Toll-like receptor adaptor molecule1 (TRIF 1) but most TLR-related genes remained unchanged (Table 2). While only slight changes of most TLR-related genes were observed at $6 \mathrm{~h}$ after SARS$\mathrm{CoV}$ infection, both the negative regulator of Toll-like receptor signaling IRAK-M and TLR7 were $>2$-fold up-regulated at $24 \mathrm{~h}$. In the mean time, the downstream molecules of Toll-like receptor pathway: MyD88, TRIF, and Toll pathway evolutional conservative (SITPEC) were all down-regulated. The expressions of other Toll-like receptors, including TLR5, TLR4, TLR2, and TLR9 remained unchanged. High expression of IRAK-M and down-regulation of the downstream signal molecules suggest that although TLR7 was up-regulated, the TLR downstream signals may not be transduced in SARSCoV infected monocytes.

The expressions of cytokines, receptors and signaling molecules are differentially regulated 
As cytokines are important immune mediators, we studied the cytokine, receptor and signal molecule gene expressions in monocytes (Table 3). While the only change of gene expression induced by CoV-229E infection was the down-regulation of IL-10R $\alpha$ at $6 \mathrm{~h}$ after infection, we observed that SARS-CoV induced the down-regulation of TNF superfamily 14 (TNFSF14) and endoglin by $>1.5$-fold at $6 \mathrm{~h}$ after infection. At $24 \mathrm{~h}$ after SARS-CoV infection, the genes that were up-regulated were TNF receptor 21 (TNFRSF 21), TNF- $\alpha$ inducible protein 1 (TNFAIP1), IL-10R $\alpha$ and IFN- $\gamma$ receptor 1 (IFN- $\gamma$ R1). Among them, the gene expression of TNF receptor 21 was up-regulated by $>2$-fold. Nevertheless, other genes in the TNF superfamily including TNF receptor associated factor 4 (TRAF4), TNF ligand family 10 (TRAIL), TNF receptor 1A (TNFRSF 1A), and TNF family 14 (TNFSF14) and those in the TGF family, TGF- $\beta 2$ (TGFB2), TGF- $\beta$ induced 68KD (TGFB1 $68 \mathrm{KD}$ ) and endoglin were $\geq 1.5$-fold down-regulated by SARS$\mathrm{CoV}$ at $24 \mathrm{~h}$ after infection. Among them, endoglin was down-regulated by $>2$-fold. Interestingly, even though IFN- $\gamma \mathrm{R} 1$ was up-regulated, IFN- $\gamma$ inducible adhesion regulating molecule 1 (ADRM1) was down-regulated. Other cytokine-related genes such as IL-6 receptor (IL-6R), cytokine-like factor1 (CLF1), IL-2 receptor-enhancing thioredoxin, and IL-13 were all down-regulated.

\section{The expressions of lysosome-related genes are differentially regulated}

Lysosomal enzymes responsible for degrading foreign proteins are important to the biological functions of macrophages [21]. While not much change was observed in the 
expression of lysosome-related genes after 229E-CoV infection except ATPase 21KD V0C and palmitoyl-protein thioesterase 1 (PPTE1), the expressions of GlcNAc phosphotransferase (GlcNAcp) and lysosome-associated protein 4 alpha (LAMP4 alpha) were down-regulated at $6 \mathrm{~h}$ after SARS-CoV infection (Table 4). At $24 \mathrm{~h}$ after SARSCoV infection, all but ATPaseV01 and glucosamine-6-sulfatase (G-6-S) lysosome-related genes were down-regulated. These genes included GlcNAc phosphotransferase (GlcNAcp), palmitoyl-protein thioesterase 2 (PPTE2), mannosidase, lysosome ATPase subunits (14KDV1F, 16KDV0C, \& 21KDV0C), lysosomal associated proteins (LAMP $4 \alpha$ and LAMP 5), adaptor-related protein complex 2, mu-1 subunit (AP2M1), and prosaposin. It is worth noting that lysosome ATPase $21 \mathrm{KDV} 0 \mathrm{C}$ and prosapsin were $>2$ fold down-regulated at $24 \mathrm{~h}$ after SARS-CoV infection. These data demonstrated that although the genes of lysosome-related enzymes were differentially regulated after SARS-CoV infection, most of them were down-regulated. The results indicate that SARS-CoV-infected monocytes lost the ability to degrade ingested proteins.

\section{The expressions of genes of the cathepsin and proteasome family are down- regulated}

The cathepsins and proteosomes are directly involved in antigen processing in the MHC class II and I pathways, respectively [22, 23]. While CoV-229E infection of monocytes did not result in much change in the cathepsin and proteosome genes, SARS-CoV infection induced down-regulation of all of them (Table 5). It was most apparent at $24 \mathrm{~h}$ after infection, that cathepsins $\mathrm{A}, \mathrm{S}, \mathrm{C}, \mathrm{H}$, and $\mathrm{D}$ as well as proteosomes $\alpha 4, \beta 2,26 \mathrm{~S}$ 
ATPase 4 (26s/A4), $\beta 9$, activator $2, \beta 3$, activator $1,26 \mathrm{~S}$ non-ATPase8 (26s nA8), and $\alpha 5$ were all down-regulated $\geq 1.5$-fold in which the changes of cathepsins $H$ and $D$ and proteosomes activator 2 , activator $1,26 \mathrm{~s} \mathrm{nA} 8$ and $\alpha 5$ gene expressions were $>2$-fold. These results show that the MHC class II and I antigen processing pathways are inhibited in SARS-CoV infected monocytes.

\section{The expressions of chaperon and MHC-related genes are differentially regulated}

To further understand the regulation of genes that are directly involved in antigen processing/presentation, chaperon and MHC-related genes were analyzed. Table 6 shows that CoV-229E induced down-regulation of SEC61B and upregulation of X-box binding protein 1, HSP70KD8, and calrecticulin genes at $6 \mathrm{~h}$ and upregulation of HSP70KD8 at $24 \mathrm{~h}$ after infection. The expressions of other chaperon and MHC-related genes remained unchanged at either 6 or $24 \mathrm{~h}$. SARS-CoV infection, however, induced upregulation of cyclophilin G and chaperonin containing TCP1-7 and down-regulation of cyclphilin C, $\mathrm{X}$-box binding protein 1, and FK506 binding protein 10 at $6 \mathrm{~h}$. By $24 \mathrm{~h}$ after SARS-CoV infection, while cyclophilins D and G and heat shock factor 1 were up-regulated, most chaperon and MHC-related genes were down-regulated. The down-regulated genes included chaperonins (chaperoinin containing TCP16A, TCP1-7, valosin-containing protein), HLA genes (HLA-B-associated transcript 2, HLA-HA1, HLA complex group 9, X-box binding protein1), FK506 binding proteins (FK506 BP8, FK506 BP10), heat shock

proteins (activator of HSP90KD, HSP10KD1, HSP70KD8), cyclophilins (E, C, B), and MHC transporters (BAP31, SEC61B, calreticulin). The expression profiles of cathepsins, 
proteosomes, cheperons, and MHC-related molecules together strongly indicate that antigen processing and presentation pathways are dysfunctional in SARS-CoV-infected monocytes.

\section{The expressions of chemokines, receptors and related genes are differentially} regulated

Given that recruitment of leukocytes to the site of inflammation is orchestrated by chemokines [24], and ARDS is characterized by heavy infiltration of monocytes, neutrophils, and fibroblasts to the lungs [25], we next examined the expression profile of chemokine-related genes. While all chemokine-related genes except MIP-1 $\alpha /$ CCL3 (down-regulated at both 6 and $24 \mathrm{~h}$ ) in the CoV-229E-infected cells remained unchanged, many of them were up- or down-regulated in SARS-CoV-infected cells (Table 7). In fact, at as early as $6 \mathrm{~h}$ after SARS-CoV infection, the down-regulation of MIP-1 $\alpha / C C L 3$, prostaglandin D synthase (PGDS), RANTES/CCL5, and LTXC4 synthase genes were already obvious. At $24 \mathrm{~h}$ after infection, those genes that were upregulated include major basic protein homolog (MBPH), CXCL8/IL-8, hyaluronidase 3, PDGF receptor $\alpha$ (PDGFR $\alpha$ ), lelukotriene A4 (LTXA4) hydroxylase, and hyaluronan-mediated motility receptor (RHMM). The expression of MBPH and CXCL8/IL-8 genes were $>2$-fold higher than the control. Others like microsomal glutathione-S transferase (MGST2), prostaglandin E synthase (PGEs), chemokine-like factor (CLF), GRO $\gamma /$ CXCL3, MGST3, MIP-1 $\alpha /$ CCL3, CCR9, RANTES/CCL5 and LTXC4 synthase were down-regulated. Among them, the expressions of CCL3/MIP-1, CCR9, RANTES/CCL5 and LTXC4 
synthase genes were $>2$-fold lower than the control. The upregulated genes (CXCL8/IL-8, hyaluronidase 3, PDGF receptor alpha, LTXA hydroxylase) are known to recruit monocytes, neutrophils, and fibroblasts which may explain the complication of ARDS in SARS-CoV infection.

\section{The expressions of fibrosis-related genes are differentially regulated}

Pulmonary fibrosis resulting from lung injury is a serious complication of ARDS and SARS. Thus, we examined whether fibrosis-related gene expression is changed after SARS infection. Data in Table 8 show that while CoV-229E infection did not change the gene expression profile except tissue inhibitor of metalloproteinase (TIMP1) and proline 2-oxoglutarate 4-dioxygenase (P4HA1) at $6 \mathrm{~h}$. SARS-CoV infection induced up- and down-regulation of fibrosis-related genes. The expression of proline 2-oxoglutarate 4dioxygenase (P4HA1), a key enzyme in collagen synthesis, was up-regulated at $6 \mathrm{~h}$ and further increased at $24 \mathrm{~h}$ after SARS-CoV infection. The other genes that were upregulated at $24 \mathrm{~h}$ include plasiminogen activator inhibitor type 2 (SERPINB2), matrix metalloproteinase 28 (MMP28), A disintingrin and metalloproteinase domain 19 (ADAM 19). On the other hand, other fibrosis-related genes were down-regulated and these include protein S, metalloproteinase 2 (MMP2), collagens XVIII $\alpha 1$, and I $\alpha 2$, spondin 2 (SPON2), procollagenlysin-2-oxoglutarate 5-dioxygenase 3 (PLOD3), metallopeptidase with thrombospondin type 1 motif 4 (ADAMTS4), fibroblast growth factor 3 (FGF3), tissue inhibitor of metalloproteinases 3 and 1 (TIMP3, TIMP1). The genes that were down-regulated by $\geq 2$-fold were FGF3, collagens XVIII $\alpha 1$, and I $\alpha 2$ and TMPs 1 and 3 . 
The regulation of fibrosis-related genes may help to explain the pathogenesis of ARDS and pulmonary fibrosis in SARS-CoV infection.

\section{The expressions of oxygen stress-related genes are up-regulated}

Change of oxygen tension is a source of stress. While CoV-229E infection did not induce oxygen stress-related genes, SARS-CoV infection induced the up-regulation of hypoxia-related genes at as early as $6 \mathrm{~h}$ and sustained until $24 \mathrm{~h}$ (Table 9). These were hypoxia-inducible 2 and hypoxia up-regulated 1 genes. The oxidative responsive 1 gene up-regulation was observed only at 24 but not at $6 \mathrm{~h}$ after infection. These results demonstrate that SARS-CoV infection of monocytes creates a hypoxic environment, which induces the expression of hypoxia-related genes. 


\section{Discussion}

Monocytes play a key role in mediating inflammatory response in the lungs of SARS patients [4]. Thus, the interaction between SARS-CoV and monocytes is important to the outcome of the infection. How SARS-CoV regulates gene expression has been a subject of interest. The peripheral blood mononuclear cells (PBMC) and monocyte gene expression profiles were analyzed. A microarray analysis of PBMC of patients recovering from SARS revealed that SARS-CoV infection causes a general suppression of gene expression and induces the up-regulation of only several specific ESTs and eosinophil-derived neurotoxins [15]. A different study showed that in contrast to CoV$229 \mathrm{E}$ and influenza (H1N1) infections, interferon- $\alpha / \beta$ signaling fails to occur in macrophages after SARS-CoV infection [5]. The results of our study showed that most of the IFN- $\alpha / \beta$ inducible, lysosome-related, cathepsin/proteosome, and MHC/chaperon genes are down-regulated, while the genes of which products play suppressive roles, i.e. IRAK-M, and IL-10R $\alpha$ are up-regulated. These results together indicate that SARS-CoV infection causes macrophage dysfunction.

TLR-7 is amongst the few genes that are up-regulated by SARS-CoV (Table 2). TLR-7 is recently shown to appear on the endosomal membrane and plays as an intracellular receptor for single-stranded RNA(ssRNA) [20, 26]. It can distinguish cellular from viral ssRNAs because the cellular RNAs contain a greater number of modified nucleotide bases (m5C, m6A, m5U, and s2U) [27]. It has not been explored whether intracellular TLR-7 binds the nucleic acid of SARS-CoV and triggers downstream signals. Our data 
showing that SARS-CoV induces the up-regulation of TLR-7 and the negative signal regulator IL-1 receptor associated kinase M (IRAK-M) and the down-regulation TLR downstream signal molecules MyD88, Toll-like receptor adaptor molecule 1 (TRIF1), and Toll pathway evolutional conservative (SITPEC) as well as most of the IFN- $\alpha / \beta$ inducible genes, demonstrate that even if TLR-7 binds to SARS-CoV nucleic acids its downstream signaling is inhibited $[28,29]$. It has been shown that Mycobacterium tuberculosis binding to DC-SIGN on dendritic cells inhibits TLR signaling and thus inhibits dendritic cell maturation [30]. It is, therefore, also possible that SARS-CoV binding to DC-SIGN on THP-1-DC-SIGN monocytes inhibits the TLR signals as it has been demonstrated in M. tuberculosis.

Cytokines are important immune mediators. SARS-CoV down-regulates most of the TNF $\alpha$-related genes and up-regulates only TNF receptor 21 (TNFRSF 21) and TNF- $\alpha$ inducible protein 1 (TNFAIP1) (Table 3). All the TGF $\beta$-related genes are downregulated (Table 3). These findings are consistent with several previous studies measuring cytokine response in SARS-CoV infected culture cells or SARS patients [3133]. In addition, while IL-10R $\alpha$ and IFN- $\gamma$ receptor 1 (IFN- $\gamma$ R1) are up-regulated, IFN- $\gamma$ inducible adhesion-regulating molecule 1 (ADRM1) is down-regulated. Therefore, although cytokine storm has been implicated as an important immune indicator for SARS, our data show that macrophages are not a likely source

Lysosomal enzymes being responsible for digesting vesicular proteins in the lysosome are important to the functions of monocytes and macrophages [34]. SARS-CoV infection 
down-regulates most lysosomal enzymes including phosphotransferase (GlcNAcp), thioesterase (PPTE2), mannosidase, and ATPase (14KDV1F, protein 1, 16KDV0C, 21KDV0C) (Table 4)._Being professional antigen-presenting cells, monocytes/macrophages process antigens through the activities of cathepsins and proteasomes and present antigens via chaperon/MHC molecules [35]. It is interesting that SARS-CoV infection down-regulates all the cathepsin and proteasome genes and most of the chaperon/MHC genes (Tables 4, 5 and 6) and that most of these downregulated genes in the proteosome family are directly or indirectly interrelated (Figure 2) seemingly rendering the monocyte/macrophage unable to process and present antigens. Thus, it appears that by down-regulating the genes that are important to antigen processing and presentation, SARS-CoV suppresses the primary functions of monocyte/macrophage. Since interferon $\alpha / \beta$ up-regulates MHC related genes, the downregulation of interferon $\alpha / \beta$ genes could be partially responsible for the down-regulation of MHC-related genes_[19]. It is our speculation that by suppressing the antigenprocessing and presentation functions of monocyte/macrophage, SARS-CoV delays specific T cell activation and thus delays its own clearance.

The clinical picture of SARS is characterized by pulmonary cellular infiltration and lung consolidation [1]. We have demonstrated infiltration of neutrophils, macrophages and $\mathrm{T}$ lymphocytes in the lungs of SARS-CoV-infected patient during early phase of infection (Yen 2006 JVI) and CXCL8/IL-8 was produced by SARS-CoV-infected monocytes. The results of microarray analysis in this study showed that in addition to CXCL8/IL-8 and major basic protein homolog $(\mathrm{MBPH})$, is up-regulated by $>2$-fold (Table 7). Pathway 
network analysis showed many genes that up-regulate CXCL8/IL-8 were up-regulated after SARS-CoV infection (Figure 2). These include C/EBP delta, CD14, complement C3, and major basic protein homologue PRG3 [36-39]. A previous study demonstrated that $\mathrm{C} / \mathrm{EBP}$ delta can substitute for IL-17 to induce neutrophil activation and accumulation [40]. Interestingly, alanyl aminopeptidase (ANPEP, Figure 2) which is known to suppress IL-8 expression [41] was down regulated after SARS-CoV infection. Taken together, SARS-CoV infection induces the up-regulation of the genes that upregulate and the down-regulation of the gene that suppresses CXCL8/IL-8, showing that inducing neutrophil migration and activation is an important event in SARS-CoVinfection.

The anti-inflammatory high-molecular mass-hyaluronan is known to be a protective factor against acute lung injury [42]. Hyaluronidase degrades high-molecule-mass hyaluronan to hyaluronan fragments [43]. In patients with acute lung injury the hyaluronan fragments are increased [42]. Through the hyaluronan-mediated motility receptor (RHMM), hyaluronan fragments mediate macrophage and neutrophil migration, increase the phagocytic function of neutrophils [44] and macrophage CXCL8/IL-8 production [45]. Interestingly, SARS-CoV infection induces the up-regulation of hyaluronidase 3, and the receptor for hyaluronan-mediated motility (RHMM) (Table 7). We speculate that through the activity of hyaluonidase 3 and increased RHMM expression, more hyaluronan fragments are produced which contribute to the increase of neutrophil and monocyte infiltration and functions. 
The relationship between leukotriene and lung fibrosis has been demonstrated in mice deficient in 5-lipoxygenase knockout mice. The knockout mice which are deficient in leukotriene are protected from lung fibrosis induced by bleomycin ([46]. No increase of inflammatory cells in the lungs was noted in the knockout mice in contrast to wild-type mice which have abundant leukocytes. Leukotriene A4 (LTXA4) hydroxylase catalyses the production of leukotiene B4 from leukotriene A4 while leukotriene C4 (LTXC4) synthases mediates the production of leukotriene C4 from leukotriene A4 [47, 48]. Our results showing down-regulation of LTXC4 synthases (LTXC4 synthase, microsomal glutathione-S-transferase2, microsomal glutathione-S-transferase3) and up-regulation of LTXA4 hydroxylase (Table 7) indicate that there is increased leukotriene B4 accumulation after SARS-CoV infection. Therefore, leukontriene B4, a potent chemoattractant for neutrophils [49], could also be accounted for the increase of neutrophil migration in the lungs.

Prostaglandin E (PGE) is commonly used as a treatment for ARDS [50]. PGE2 inhibits fibroblast proliferation, collagen synthesis and fibroblast chemotaxis [51]. In cycloxygenase-2-deficient mice, the severity of intratracheal bleomycin-induced lung fibrosis is increased due to PGE2 reduction [52]. It is worth noting that both prostaglandin E and prostaglandin D synthetases (PGES and PGDS) are down-regulated in SARS-CoV infected cells (Table 7) implying the PGE2 level is reduced in SARS patients which may contribute to lung fibrosis. Platelet-derived growth factor (PDGF) is a major fibroblast mitogen [53] . It also serves as a chemoattractant for neutrophils, monocytes, and fibroblasts [54]. Therefore, up-regulation of PDGF receptor $\alpha$ by SARS- 
$\mathrm{CoV}$ (Table 7) through PDGF signaling would result in fibroblast proliferation, neutrophil and monocyte infiltration and worsened lung fibrosis [55].

Lung fibrosis is a squeal of severe acute pulmonary disease [7]. It is thus of interest to understand how SARS-CoV affects the expression of fibrosis-related genes. A previous study revealed that collagen III is up-regulated in ARDS and its levels are related to poor prognosis [56]. Proline 2-oxoglutarate 4-dioxygenase (P4HA1), a key enzyme in collagen synthesis is up-regulated but collagen I $\alpha 2$ and collagen XVIII $\alpha 1$ are downregulated by SARS-CoV infection (Table 8)._Studies have also shown that tissue inhibitors of metalloproteinases (TIMP) deficiency or TIMP/MMP (Matrix metalloproteinase) imbalance contributes to $[57,58]$ and plasminogen activator inhibitor (SERPINB2) deficiency protects against pulmonary fibrosis [59]. _Fibrinolytic proteins are protective against lung fibrosis [60]. SARS-CoV infection up-regulates proteinases: matrix metalloproteinase 28 (MMP28), A disintegrin and metalloproteinase domain 19 (ADM19), and plasminogen activator inhibitor (SERPINB2) and down-regulates tissue inhibitors of metalloproteinases 1 and 3 (TIMP1 and TIMP3) and fibrinolytic protein (protein S) (Table 8). Our data showing the up- and down-regulation of fibrosis-related genes provide the molecular basis of the clinical presentation of pulmonary fibrosis in SARS.

\section{Conclusion}

In summary, our study of the gene profiles in macrophages after SARS-CoV infection show that the expressions of (i) IFN- $\alpha / \beta$-inducible and cathepsin/proteosome genes are 
down-regulated; (ii) the hypoxia/heperoxia-related gene are up-regulated; and (iii) the TLR/TLR-signaling, cytokine/cytokine receptor-related, chemokine/chemokine receptorrelated, the lysosome-related, $\mathrm{MHC} /$ chaperon-related, and fibrosis-related genes are differentially regulated. _These results demonstrate that SARS-CoV infection causes monocyte/macrophage dysfunction and induces pulmonary fibrosis both of which are important in the pathogenesis of SARS.

\section{List of Abbreviations:}

ADAMTS4: metallopeptidase with thrombospondin type 1 motif 4; ADRM1: adhesion regulating molecule 1; AP2M1: adaptor-related protein complex 2,mu-1 subunit; ARDS: acute respiratory distress syndrome; CLF1: cytokine-like factor 1; CMV: cytomegalovirus; CoV-229E: coronavirus 229E; E. coli: Escherichia coli; EIF2: eukaryotic translation initiation factor 2; FGF3: fibroblast growth factor 3; FK506BP: FK506 binding protein; GIP: interferon inducible guanylate binding protein; GlcNAcp: GlcNAc phosphotransferase; G-6-S: glucosamine-6-sulfatase; HIV: human immunodeficiency virus; HLA: human leukocyte antigen; HSP: heat shock protein; IFN: interferon; IRAK: serine/threonine innate immunity kinase; ISGF3G: interferon stimulated 3 gamma; LAMP: lysosomal associated protein; LTXA4: leukotriene A4; LTXC4: leukotriene C4;MBPH: major basic protein homolog; MGST: microsomal glutathione-S transferase; MHC: major histocompatibility complex; MMP: metalloproteinase; MX1: interferon inducible myxovirus resistance 1; OAS: oligoadenylate synthetase; PGDS: prostaglandin D synthase; PGES: prostaglandin E synthase; PLOD3: procollagenlysin-2-oxoglutarate 5-dioxygenase 3; PPTE1: palmitoyl- 
protein thioesterase 1; P4HA1: proline 2-oxoglutarate 4-dioxygenase; RHMM: hyaluronan-mediated motility receptor; SARS: severe acute respiratory syndrome; SARS-CoV: SARS coronavirus; SERPINB2: plasminogen activator inhibitor type2; SITPEC: Toll pathway evolutional conservative; SPON2: spondin 2; TIMP: tissue inhibitor of metalloproteinase; TLR: Toll-like receptor; TGFB1 68KD: TGF beta induced 68KD; TNFAIP1: TNF alpha inducible protein1; TNFRSF1A: TNF receptor 1A; TNFRSF21: TNF receptor 21; TNFSF14: TNF family 14; TRAF4: TNF receptor associated factor 4; TRAIL: TNF ligand family 10; TRIF1: Toll-like receptor adaptor molecule 1

\section{Competing interests}

This study is funded by National Science Council of Taiwan government. There are no financial competing interests or non-financial competing interests in this research.

\footnotetext{
Author's contributions

WJ Hu carried out monocytic cell culture, total RNA extraction, chip hybridization preparation, and data analysis with interpretation. He also helps in the study design and to draft this manuscript. YT Yen performed the SARS-CoV infection on THP-1 monocytic cell lines. S Singh participated in the data analysis and network graphing. CL Kao kindly provided coronavirus 229E and SARS-CoV with estimated virus titer. BA Wu-Hsieh designed this study and she is also the coordinator, sponsor, and corresponding author of this research. All authors read and approved the final manuscript.
} 


\begin{abstract}
About the author
Wan-Jiung $\mathrm{Hu}$ is a MD from National Taiwan University and $\mathrm{PhD}$ from vaccine science track of Department of International Health of Johns Hopkins University. His $\mathrm{PhD}$ thesis is using microarray analysis to study the complicated host immune response against malarial infection. This SARS-microarray paper was finished in Graduate Institute of Immunology of National Taiwan University when Wan-Jiung was served as an exchange student during 2005-2006. His first author paper is entitled "Common and divergent immune response signaling pathways discovered in peripheral blood mononuclear cell gene expression patterns in presymptomatic and clinically apparent malaria" published in Infection and Immunity in October 2006. Now, Wan-Jiung Hu is doing a postdoc research about cancer immunotherapy in Genomic Research Center of Academia Sinica of Taiwan.
\end{abstract}

\title{
Acknowledgements
}

The authors are grateful to Mong-Hsien Tsai, Chang-Hsui Sun, Hang-Ni Lee, Hsang-Un Hsiao, Hsin-Yi Chang, and Hui-Zhu Yang and personnel in the Biosafty Level 3 Laboratory in the National Taiwan University Hospital and National Taiwan University College of Medicine for their technical assistance.

\section{References}

1. Skowronski DM, Astell C, Brunham RC, Low DE, Petric M, Roper RL, Talbot PJ, Tam T, Babiuk L: Severe acute respiratory syndrome (SARS): a year in review. Annu Rev Med 2005, 56:357-381. 
2. Peiris JS, Chu CM, Cheng VC, Chan KS, Hung IF, Poon LL, Law KI, Tang BS, Hon TY, Chan CS, et al: Clinical progression and viral load in a community outbreak of coronavirus-associated SARS pneumonia: a prospective study. Lancet 2003, 361:1767-1772.

3. Grinblat L, Shulman H, Glickman A, Matukas L, Paul N: Severe acute respiratory syndrome: radiographic review of 40 probable cases in Toronto, Canada. Radiology 2003, 228:802-809.

4. Nicholls JM, Poon LL, Lee KC, Ng WF, Lai ST, Leung CY, Chu CM, Hui PK, Mak KL, Lim W, et al: Lung pathology of fatal severe acute respiratory syndrome. Lancet 2003, 361:1773-1778.

5. Cheung CY, Poon LL, Ng IH, Luk W, Sia SF, Wu MH, Chan KH, Yuen KY, Gordon S, Guan Y, Peiris JS: Cytokine responses in severe acute respiratory syndrome coronavirus-infected macrophages in vitro: possible relevance to pathogenesis. J Virol 2005, 79:7819-7826.

6. Yen YT, Liao F, Hsiao CH, Kao CL, Chen YC, Wu-Hsieh BA: Modeling the early events of severe acute respiratory syndrome coronavirus infection in vitro. J Virol 2006, 80:2684-2693.

7. Antonio GE, Wong KT, Hui DS, Wu A, Lee N, Yuen EH, Leung CB, Rainer TH, Cameron $\mathrm{P}$, Chung SS, et al: Thin-section CT in patients with severe acute respiratory syndrome following hospital discharge: preliminary experience. Radiology 2003, 228:810-815.

8. Lau YL, Peiris JS: Pathogenesis of severe acute respiratory syndrome. Curr Opin Immunol 2005, 17:404-410.

9. Zhu H, Cong JP, Mamtora G, Gingeras T, Shenk T: Cellular gene expression altered by human cytomegalovirus: global monitoring with oligonucleotide arrays. Proc Natl Acad Sci U S A 1998, 95:14470-14475.

10. Bleharski JR, Li H, Meinken C, Graeber TG, Ochoa MT, Yamamura M, Burdick A, Sarno EN, Wagner M, Rollinghoff M, et al: Use of genetic profiling in leprosy to discriminate clinical forms of the disease. Science 2003, 301:15271530.

11. van 't Wout AB, Lehrman GK, Mikheeva SA, O'Keeffe GC, Katze MG, Bumgarner RE, Geiss GK, Mullins JI: Cellular gene expression upon human immunodeficiency virus type 1 infection of CD4(+)-T-cell lines. J Virol 2003, 77:1392-1402.

12. Cheung CY, Poon LL, Lau AS, Luk W, Lau YL, Shortridge KF, Gordon S, Guan $Y$, Peiris JS: Induction of proinflammatory cytokines in human macrophages by influenza A (H5N1) viruses: a mechanism for the unusual severity of human disease? Lancet 2002, 360:1831-1837.

13. Eickhoff M, Thalmann J, Hess S, Martin M, Laue T, Kruppa J, Brandes G, Klos A: Host cell responses to Chlamydia pneumoniae in gamma interferoninduced persistence overlap those of productive infection and are linked to genes involved in apoptosis, cell cycle, and metabolism. Infect Immun 2007, 75:2853-2863.

14. Ramilo O, Allman W, Chung W, Mejias A, Ardura M, Glaser C, Wittkowski KM, Piqueras B, Banchereau J, Palucka AK, Chaussabel D: Gene expression patterns 
in blood leukocytes discriminate patients with acute infections. Blood 2007, 109:2066-2077.

15. Lee Y, Chen C, Chao A, Chen E, Wei M: Molecular signature of clinical severity in recovering patients with severe acute respiratory syndrome coronavirus(SARS-CoV). BMC Genomics 2005, 6:1-10.

16. Soilleux EJ, Morris LS, Leslie G, Chehimi J, Luo Q, Levroney E, Trowsdale J, Montaner LJ, Doms RW, Weissman D, et al: Constitutive and induced expression of DC-SIGN on dendritic cell and macrophage subpopulations in situ and in vitro. J Leukoc Biol 2002, 71:445-457.

17. Hsueh PR, Hsiao CH, Yeh SH, Wang WK, Chen PJ, Wang JT, Chang SC, Kao CL, Yang PC: Microbiologic characteristics, serologic responses, and clinical manifestations in severe acute respiratory syndrome, Taiwan. Emerg Infect Dis 2003, 9:1163-1167.

18. Tsai MH, Yan H, Chen X, Chandramouli GV, Zhao S, Coffin D, Coleman CN, Mitchell JB, Chuang EY: Evaluation of hybridization conditions for spotted oligonucleotide-based DNA microarrays. Mol Biotechnol 2005, 29:221-224.

19. Samuel CE: Antiviral actions of interferons. Clin Microbiol Rev 2001, 14:778809 , table of contents.

20. Lund JM, Alexopoulou L, Sato A, Karow M, Adams NC, Gale NW, Iwasaki A, Flavell RA: Recognition of single-stranded RNA viruses by Toll-like receptor 7. Proc Natl Acad Sci U S A 2004, 101:5598-5603.

21. Amer AO, Swanson MS: A phagosome of one's own: a microbial guide to life in the macrophage. Curr Opin Microbiol 2002, 5:56-61.

22. Elliott T, Neefjes J: The complex route to MHC class I-peptide complexes. Cell 2006, 127:249-251.

23. Hsing LC, Rudensky AY: The lysosomal cysteine proteases in MHC class II antigen presentation. Immunol Rev 2005, 207:229-241.

24. Charo IF, Ransohoff RM: The many roles of chemokines and chemokine receptors in inflammation. $N$ Engl $J$ Med 2006, 354:610-621.

25. Ware LB, Matthay MA: The acute respiratory distress syndrome. $N$ Engl $J$ Med 2000, 342:1334-1349.

26. Heil F, Hemmi H, Hochrein H, Ampenberger F, Kirschning C, Akira S, Lipford G, Wagner H, Bauer S: Species-specific recognition of single-stranded RNA via toll-like receptor 7 and 8. Science 2004, 303:1526-1529.

27. Kariko K, Buckstein M, Ni H, Weissman D: Suppression of RNA recognition by Toll-like receptors: the impact of nucleoside modification and the evolutionary origin of RNA. Immunity 2005, 23:165-175.

28. Schoenemeyer A, Barnes BJ, Mancl ME, Latz E, Goutagny N, Pitha PM, Fitzgerald KA, Golenbock DT: The interferon regulatory factor, IRF5, is a central mediator of toll-like receptor 7 signaling. $J$ Biol Chem 2005, 280:17005-17012.

29. Uematsu S, Sato S, Yamamoto M, Hirotani T, Kato H, Takeshita F, Matsuda M, Coban $\mathrm{C}$, Ishii KJ, Kawai T, et al: Interleukin-1 receptor-associated kinase-1 plays an essential role for Toll-like receptor (TLR)7- and TLR9-mediated interferon-\{alpha\} induction. $J \operatorname{Exp}$ Med 2005, 201:915-923. 
30. van Kooyk Y, Geijtenbeek TB: DC-SIGN: escape mechanism for pathogens. Nat Rev Immunol 2003, 3:697-709.

31. Reghunathan R, Jayapal M, Hsu LY, Chng HH, Tai D, Leung BP, Melendez AJ: Expression profile of immune response genes in patients with Severe Acute Respiratory Syndrome. BMC Immunol 2005, 6:2.

32. Spiegel M, Weber F: Inhibition of cytokine gene expression and induction of chemokine genes in non-lymphatic cells infected with SARS coronavirus. Virol J 2006, 3:17.

33. Ziegler T, Matikainen S, Ronkko E, Osterlund P, Sillanpaa M, Siren J, Fagerlund $\mathrm{R}$, Immonen M, Melen K, Julkunen I: Severe acute respiratory syndrome coronavirus fails to activate cytokine-mediated innate immune responses in cultured human monocyte-derived dendritic cells. J Virol 2005, 79:1380013805.

34. Unanue ER, Beller DI, Calderon J, Kiely JM, Stadecker MJ: Regulation of immunity and inflammation by mediators from macrophages. Am J Pathol 1976, 85:465-478.

35. Overath $\mathrm{P}$, Aebischer $\mathrm{T}$ : Antigen presentation by macrophages harboring intravesicular pathogens. Parasitol Today 1999, 15:325-332.

36. Dentener MA, Bazil V, Von Asmuth EJ, Ceska M, Buurman WA: Involvement of CD14 in lipopolysaccharide-induced tumor necrosis factor-alpha, IL-6 and IL-8 release by human monocytes and alveolar macrophages. J Immunol 1993, 150:2885-2891.

37. Wu GD, Lai EJ, Huang N, Wen X: Oct-1 and CCAAT/enhancer-binding protein $(\mathrm{C} / \mathrm{EBP})$ bind to overlapping elements within the interleukin-8 promoter. The role of Oct-1 as a transcriptional repressor. J Biol Chem 1997, 272:2396-2403.

38. Vecchiarelli A, Retini C, Casadevall A, Monari C, Pietrella D, Kozel TR: Involvement of C3a and C5a in interleukin-8 secretion by human polymorphonuclear cells in response to capsular material of Cryptococcus neoformans. Infect Immun 1998, 66:4324-4330.

39. Plager DA, Loegering DA, Weiler DA, Checkel JL, Wagner JM, Clarke NJ, Naylor S, Page SM, Thomas LL, Akerblom I, et al: A novel and highly divergent homolog of human eosinophil granule major basic protein. $J$ Biol Chem 1999, 274:14464-14473.

40. Ruddy MJ, Wong GC, Liu XK, Yamamoto H, Kasayama S, Kirkwood KL, Gaffen SL: Functional cooperation between interleukin-17 and tumor necrosis factor-alpha is mediated by CCAAT/enhancer-binding protein family members. $J$ Biol Chem 2004, 279:2559-2567.

41. Kanayama N, Kajiwara Y, Goto J, el Maradny E, Maehara K, Andou K, Terao T: Inactivation of interleukin-8 by aminopeptidase N (CD13). J Leukoc Biol 1995, 57:129-134.

42. Jiang D, Liang J, Fan J, Yu S, Chen S, Luo Y, Prestwich GD, Mascarenhas MM, Garg HG, Quinn DA, et al: Regulation of lung injury and repair by Toll-like receptors and hyaluronan. Nat Med 2005, 11:1173-1179.

43. Stern R, Asari AA, Sugahara KN: Hyaluronan fragments: an information-rich system. Eur J Cell Biol 2006, 85:699-715. 
44. Hakansson L, Venge P: The molecular basis of the hyaluronic acid-mediated stimulation of granulocyte function. J Immunol 1987, 138:4347-4352.

45. McKee CM, Penno MB, Cowman M, Burdick MD, Strieter RM, Bao C, Noble PW: Hyaluronan (HA) fragments induce chemokine gene expression in alveolar macrophages. The role of HA size and CD44. J Clin Invest 1996, 98:2403-2413.

46. Peters-Golden M, Bailie M, Marshall T, Wilke C, Phan SH, Toews GB, Moore $\mathrm{BB}$ : Protection from pulmonary fibrosis in leukotriene-deficient mice. $\mathrm{Am} \mathrm{J}$ Respir Crit Care Med 2002, 165:229-235.

47. Minami M, Ohno S, Kawasaki H, Radmark O, Samuelsson B, Jornvall H, Shimizu T, Seyama Y, Suzuki K: Molecular cloning of a cDNA coding for human leukotriene A4 hydrolase. Complete primary structure of an enzyme involved in eicosanoid synthesis. J Biol Chem 1987, 262:13873-13876.

48. Lam BK, Penrose JF, Freeman GJ, Austen KF: Expression cloning of a cDNA for human leukotriene $\mathrm{C} 4$ synthase, an integral membrane protein conjugating reduced glutathione to leukotriene A4. Proc Natl Acad Sci U S A 1994, 91:7663-7667.

49. Palmblad J, Malmsten CL, Uden AM, Radmark O, Engstedt L, Samuelsson B: Leukotriene B4 is a potent and stereospecific stimulator of neutrophil chemotaxis and adherence. Blood 1981, 58:658-661.

50. van Heerden PV, Barden A, Michalopoulos N, Bulsara MK, Roberts BL: Doseresponse to inhaled aerosolized prostacyclin for hypoxemia due to ARDS. Chest 2000, 117:819-827.

51. Bitterman PB, Wewers MD, Rennard SI, Adelberg S, Crystal RG: Modulation of alveolar macrophage-driven fibroblast proliferation by alternative macrophage mediators. J Clin Invest 1986, 77:700-708.

52. Hodges RJ, Jenkins RG, Wheeler-Jones CP, Copeman DM, Bottoms SE, Bellingan GJ, Nanthakumar CB, Laurent GJ, Hart SL, Foster ML, McAnulty RJ: Severity of lung injury in cyclooxygenase-2-deficient mice is dependent on reduced prostaglandin E(2) production. Am J Pathol 2004, 165:1663-1676.

53. Warshamana GS, Martinez S, Lasky JA, Corti M, Brody AR: Dexamethasone activates expression of the PDGF-alpha receptor and induces lung fibroblast proliferation. Am J Physiol 1998, 274:L499-507.

54. Siegbahn A, Hammacher A, Westermark B, Heldin CH: Differential effects of the various isoforms of platelet-derived growth factor on chemotaxis of fibroblasts, monocytes, and granulocytes. J Clin Invest 1990, 85:916-920.

55. Abdollahi A, Li M, Ping G, Plathow C, Domhan S, Kiessling F, Lee LB, McMahon G, Grone HJ, Lipson KE, Huber PE: Inhibition of platelet-derived growth factor signaling attenuates pulmonary fibrosis. $J$ Exp Med 2005, 201:925-935.

56. Clark JG, Milberg JA, Steinberg KP, Hudson LD: Type III procollagen peptide in the adult respiratory distress syndrome. Association of increased peptide levels in bronchoalveolar lavage fluid with increased risk for death. Ann Intern Med 1995, 122:17-23.

57. Kim KH, Burkhart K, Chen P, Frevert CW, Randolph-Habecker J, Hackman RC, Soloway PD, Madtes DK: Tissue inhibitor of metalloproteinase-1 deficiency 
amplifies acute lung injury in bleomycin-exposed mice. Am J Respir Cell Mol Biol 2005, 33:271-279.

58. Ruiz V, Ordonez RM, Berumen J, Ramirez R, Uhal B, Becerril C, Pardo A, Selman M: Unbalanced collagenases/TIMP-1 expression and epithelial apoptosis in experimental lung fibrosis. Am J Physiol Lung Cell Mol Physiol 2003, 285:L1026-1036.

59. Hattori N, Mizuno S, Yoshida Y, Chin K, Mishima M, Sisson TH, Simon RH, Nakamura T, Miyake M: The plasminogen activation system reduces fibrosis in the lung by a hepatocyte growth factor-dependent mechanism. Am J Pathol 2004, 164:1091-1098.

60. Kotani I, Sato A, Hayakawa H, Urano T, Takada Y, Takada A: Increased procoagulant and antifibrinolytic activities in the lungs with idiopathic pulmonary fibrosis. Thromb Res 1995, 77:493-504.

Figure legends

Figure 1.

Heatmap image of microarray analysis result of SARS-CoV and $\mathrm{CoV}-229 \mathrm{E}$ infected THP1-DC-SIGN cells. S6M: SARS 6h mean, S6A: SARS 6h sample A, S6B: SARS 6h sample B; E6M: CoV-229E 6h mean, E6A: Cov-229E 6h sample A, E6B: CoV-229E 6h sample B; S24M: SARS 24h mean, S24A: SARS 24h sample A, S24B: SARS 24h sample B; E24M: CoV-229E 24h mean, E24A: Cov-229E 24h sample A, E24B: CoV229E 24h sample B

Figure 2

Pathway analysis of specific gene-to-gene network of IL-8 and proteosome families. Red and green colors denote up-regulation and down-regulation, respectively. Darker color indicates greater up- or down-regulation and lighter color mild to moderate up- or down-regulation. Solid and dotted lines lines indicate direct and indirect up-regulation from upstream gene A to downstream gene B, respectively. Straight lines with blunt end indicate down-regulation from upstream gene A to downstream gene B. 
$\underline{\text { Table 1. Interferon } \alpha / \beta \text { inducible gene expressions }}$

\begin{tabular}{|c|c|c|c|c|c|c|c|c|c|c|c|c|c|}
\hline \multirow{4}{*}{ Gene } & \multirow{4}{*}{$\begin{array}{l}\text { GeneBank } \\
\text { Accession } \\
\text { Number }\end{array}$} & \multicolumn{12}{|c|}{ Fold change $^{*} \dagger$} \\
\hline & & \multicolumn{6}{|c|}{$6 \mathrm{~h}$} & \multicolumn{6}{|c|}{$24 \mathrm{~h}$} \\
\hline & & \multicolumn{4}{|c|}{ SARS- CoV } & \multicolumn{2}{|c|}{ Cov-229E } & \multicolumn{4}{|c|}{ SARS- CoV } & \multicolumn{2}{|c|}{ CoV- 229E } \\
\hline & & Mean & A & B & Mean & A & B & Mean & A & B & Mean & A & B \\
\hline Interferon alpha14 & NM002172 & 0.95 & 0.96 & 0.93 & 1.34 & 1.78 & 0.90 & $\underline{0.66}$ & 0.41 & 0.91 & 1.11 & 1.10 & 1.12 \\
\hline $\mathrm{ISF} \mathrm{g}^{\ddagger}$ & NM006084 & 1.04 & 0.97 & 1.10 & 1.00 & 1.00 & 1.00 & $\underline{0.62}$ & 0.54 & 0.69 & 1.01 & 1.05 & 1.11 \\
\hline IFN exonuclease & NM002201 & 0.93 & 0.96 & 0.90 & 1.03 & 1.51 & 0.56 & $\underline{0.62}$ & 0.43 & 0.81 & 0.99 & 1.01 & 0.98 \\
\hline $\mathrm{EIF} 2 \mathrm{Ak}^{\S}$ & NM002759 & 0.98 & 0.88 & 1.08 & 2.05 & 2.55 & 1.55 & $\underline{0.58}$ & 0.54 & 0.62 & 1.25 & 1.18 & 0.97 \\
\hline IFN inducible IFI35 & NM005533 & $\underline{0.58}$ & 0.49 & 0.67 & 1.09 & 1.00 & 1.18 & $\underline{0.55}$ & 0.61 & 0.49 & 0.80 & 0.83 & 1.32 \\
\hline IFN inducible G1P3 & NM002038 & $\underline{0.28}$ & 0.25 & 0.31 & 0.96 & 0.84 & 1.08 & $\underline{0.39}$ & 0.32 & 0.46 & $\underline{0.57}$ & 0.57 & 0.77 \\
\hline $2,5 \mathrm{OAS} 2^{\dagger \dagger}$ & NM002535 & $\underline{0.28}$ & 0.30 & 0.26 & 1.47 & 1.00 & 1.95 & $\underline{0.34}$ & 0.42 & 0.26 & 0.76 & 0.73 & 0.58 \\
\hline$M \times 1^{\ddagger \ddagger}$ & NM002462 & $\underline{0.40}$ & 0.35 & 0.44 & 1.07 & 0.95 & 1.19 & $\underline{0.28}$ & 0.31 & 0.24 & $\underline{0.64}$ & 0.65 & 0.80 \\
\hline Interferon inucible 44 & $\underline{\text { NM006417 }}$ & $\underline{0.32}$ & 0.27 & 0.37 & 1.28 & 0.96 & 1.59 & $\underline{0.26}$ & 0.34 & 0.18 & 0.93 & 0.90 & 0.62 \\
\hline IFN inducible G1P2 $2^{\S \S}$ & NM005101 & $\underline{0.61}$ & 0.55 & 0.66 & $\underline{0.64}$ & 0.70 & 0.57 & $\underline{0.20}$ & 0.19 & 0.21 & $\underline{0.58}$ & 0.57 & 0.95 \\
\hline
\end{tabular}

\footnotetext{
$*$

${ }^{\dagger}$ Bold face: up-regulation>1.5x; Underlined boldface: down-regulation<0.67x

*ISF3g: IFN-stimulated 3 gamma

$\S$ EIF2AK: RNA activated protein kinase

** IFN inducible G1P3: IFN inducible guanylate binding protein 3

${ }^{\dagger \dagger}$ 2,5OAS2: 2,5 oligoadenylate synthetase 2

\# MX1: myxovirus resistance 1

$\S \S$ IFN inducible G1P2: IFN guanylate binding protein 2
} 
Table 2. Toll-like signaling gene expressions

\begin{tabular}{|c|c|c|c|c|c|c|c|c|c|c|c|c|c|}
\hline \multirow{4}{*}{ Group/Gene } & \multirow{4}{*}{$\begin{array}{c}\text { GeneBank } \\
\text { Accession } \\
\text { Number }\end{array}$} & \multicolumn{12}{|c|}{ Fold change ${ }^{*}$} \\
\hline & & \multicolumn{6}{|c|}{$6 \mathrm{~h}$} & \multicolumn{6}{|c|}{$24 \mathrm{~h}$} \\
\hline & & \multicolumn{4}{|c|}{ SARS-CoV } & \multicolumn{2}{|c|}{ CoV-229E } & \multicolumn{4}{|c|}{ SARS-CoV } & \multicolumn{2}{|c|}{ CoV- 229E } \\
\hline & & Mean & A & B & Mean & A & $\mathrm{B}$ & Mean & A & $\mathrm{B}$ & Mean & A & $\mathrm{B}$ \\
\hline \multicolumn{14}{|c|}{ Toll-like signaling: } \\
\hline IRAK-M $^{\dagger}$ & $\underline{\text { NM007199 }}$ & 1.00 & 1.00 & 1.00 & 1.00 & 1.00 & 1.00 & 2.35 & 2.51 & 2.19 & 1.36 & 1.40 & 1.31 \\
\hline MyD88 ${ }^{\ddagger}$ & NM002468 & 0.90 & 0.78 & 1.01 & 0.77 & 1.00 & 0.53 & $\underline{0.63}$ & 0.68 & 0.59 & 0.98 & 1.01 & 0.94 \\
\hline TRIF $^{\S}$ & NM014261 & 0.73 & 0.66 & 0.81 & 1.57 & 1.73 & 1.40 & $\underline{0.60}$ & 0.40 & 0.80 & 1.12 & 1.07 & 1.16 \\
\hline SITPEC ${ }^{* *}$ & NM016581 & 0.73 & 0.79 & 0.67 & 1.00 & 1.00 & 0.99 & $\underline{0.51}$ & 0.43 & 0.59 & 0.93 & 0.91 & 0.95 \\
\hline \multicolumn{14}{|c|}{ TLR molecules: } \\
\hline TLR7 & NM016562 & 1.17 & 1.35 & 1.00 & 1.00 & 1.00 & 1.00 & 2.10 & 1.84 & 2.36 & 1.03 & 1.01 & 1.04 \\
\hline TLR5 & NM003268 & 0.78 & 0.72 & 0.83 & 0.97 & 1.10 & 0.83 & 1.32 & 1.16 & 1.48 & 1.01 & 1.05 & 0.97 \\
\hline TLR4 & NM003266 & 1.19 & 1.39 & 1.00 & 1.00 & 1.00 & 1.00 & 1.27 & 1.54 & 1.00 & 0.98 & 0.96 & 1.00 \\
\hline TLR2 & NM003264 & 1.06 & 1.13 & 1.00 & 1.00 & 1.00 & 1.00 & 1.12 & 1.22 & 1.01 & 1.03 & 1.02 & 1.04 \\
\hline TLR9 & NM017442 & 0.88 & 0.95 & 0.82 & 1.11 & 1.00 & 1.22 & 0.71 & 0.81 & 0.61 & 1.00 & 1.03 & 0.98 \\
\hline
\end{tabular}

* Bold face: up-regulation>1.5x; Underlined boldface: down-regulation< $<0.67 x$

${ }^{\dagger}$ IRAK-M: IL-1 receptor associated kinase-M

${ }^{\ddagger}$ MyD88: myeloid differentiation protein 88

$\S$ TRIF: Toll-like receptor adaptor molecule 1

** SITPEC: Toll pathway evolutional conservative 
Table 3. Cytokine-related gene expressions

\begin{tabular}{|c|c|c|c|c|c|c|c|c|c|c|c|c|c|}
\hline \multirow{4}{*}{ Group/Gene } & \multirow{4}{*}{$\begin{array}{c}\text { GeneBank } \\
\text { Accession } \\
\text { Number }\end{array}$} & \multicolumn{12}{|c|}{ Fold change $^{*}$} \\
\hline & & \multicolumn{6}{|c|}{$6 \mathrm{~h}$} & \multicolumn{6}{|c|}{$24 \mathrm{~h}$} \\
\hline & & \multicolumn{4}{|c|}{ SARS- CoV } & \multicolumn{2}{|c|}{ CoV-229E } & \multicolumn{4}{|c|}{ SARS-CoV } & \multicolumn{2}{|c|}{ CoV-229E } \\
\hline & & Mean & $\mathrm{A}$ & $B$ & Mean & $\mathrm{A}$ & $\mathrm{B}$ & Mean & $\mathrm{A}$ & $B$ & Mean & $\mathrm{A}$ & $\mathrm{B}$ \\
\hline \multicolumn{14}{|c|}{ TNFsuperfamily: } \\
\hline TNFRSF $21^{\dagger}$ & $\underline{\text { NM614452 }}$ & 1.00 & 1.00 & 1.00 & 1.00 & 1.00 & 1.00 & 2.23 & 2.16 & 2.30 & 1.11 & 1.06 & 1.17 \\
\hline TNFAIP $^{\ddagger}$ & $\underline{\text { NM021137 }}$ & 1.05 & 1.10 & 1.00 & 1.00 & 1.00 & 1.00 & 1.93 & 2.55 & 1.32 & 0.85 & 0.81 & 0.88 \\
\hline TRAF $^{\S}$ & $\underline{\mathrm{NM} 004295}$ & 0.72 & 0.68 & 0.77 & 1.11 & 1.80 & 0.41 & $\underline{0.67}$ & 0.49 & 0.86 & 0.96 & 0.99 & 0.92 \\
\hline TRAIL* & $\underline{\text { NM003810 }}$ & 0.94 & 0.99 & 0.88 & 1.05 & 1.00 & 1.10 & $\underline{0.64}$ & 0.52 & 0.75 & 0.76 & 0.73 & 0.79 \\
\hline TNFRSF1 $A^{\dagger \dagger}$ & $\underline{\text { AK130807 }}$ & 1.11 & 0.88 & 1.35 & 1.69 & 2.85 & 0.52 & $\underline{0.61}$ & 0.50 & 0.73 & 0.95 & 0.97 & 0.94 \\
\hline TNFSF14 & $\underline{\text { NM003807 }}$ & $\underline{0.64}$ & 0.59 & 0.69 & 1.34 & 1.87 & 0.81 & $\underline{0.55}$ & 0.46 & 0.63 & 0.93 & 0.94 & 0.91 \\
\hline \multicolumn{14}{|l|}{ TGFB-related: } \\
\hline TGFB2 & $\underline{\text { NM003242 }}$ & 1.06 & 1.00 & 1.12 & 0.87 & 1.13 & 0.61 & $\underline{0.65}$ & 0.48 & 0.82 & 0.93 & 1.01 & 0.85 \\
\hline TGFBI68KD & $\underline{N M 000358}$ & 0.81 & 0.73 & 0.90 & 1.11 & 1.68 & 0.54 & $\underline{0.64}$ & 0.37 & 0.91 & 0.95 & 0.95 & 0.95 \\
\hline Endoglin & $\underline{\text { NM000118 }}$ & $\underline{0.65}$ & 0.63 & 0.66 & 1.09 & 1.25 & 0.94 & $\underline{0.27}$ & 0.26 & 0.29 & 0.72 & 0.76 & 0.68 \\
\hline \multicolumn{14}{|c|}{ Interleukin-related } \\
\hline IL10Ra ${ }^{\S \S}$ & NM001558 & 0.91 & 0.82 & 1.00 & $\underline{0.60}$ & 1.00 & 0.20 & 1.88 & 2.03 & 1.74 & 1.01 & 1.08 & 0.93 \\
\hline IL6R & NM181359 & 0.83 & 0.79 & 0.88 & 1.17 & 1.00 & 1.34 & $\underline{0.66}$ & 0.46 & 0.86 & 1.12 & 1.16 & 1.08 \\
\hline CLF1 ${ }^{* * *}$ & NM001330 & 0.71 & 0.71 & 0.71 & 0.90 & 1.19 & 0.61 & $\underline{0.67}$ & 0.41 & 0.92 & 1.01 & 1.06 & 0.95 \\
\hline Thioredoxin & $\underline{\text { NM003329 }}$ & 1.07 & 0.91 & 1.24 & 0.74 & 0.66 & 0.81 & $\underline{0.64}$ & 0.43 & 0.85 & 0.98 & 0.99 & 0.96 \\
\hline IL13 & $\underline{\text { NM002188 }}$ & 0.76 & 0.84 & 0.69 & 1.33 & 1.52 & 1.14 & $\underline{0.55}$ & 0.36 & 0.74 & 1.01 & 0.95 & 1.08 \\
\hline \multicolumn{14}{|l|}{ IFN-g related: } \\
\hline Interferon-g R1 & $\underline{\text { NM006416 }}$ & 1.27 & 1.42 & 1.11 & 1.80 & 3.20 & 0.40 & 1.78 & 1.35 & 2.22 & 1.12 & 1.13 & 1.11 \\
\hline ADRM1 $1^{\dagger+t}$ & NM007002 & 1.14 & 1.21 & 1.06 & 0.79 & 1.00 & 0.57 & $\underline{0.55}$ & 0.62 & 0.48 & 0.88 & 0.86 & 0.90 \\
\hline
\end{tabular}

* Bold face=Up-regulation $>1.5 x$; Underlined boldface=down-regulation $<0.67 x$

† TNFRSF21: TNF receptor superfamily 21

‡ TNFAIP1: TNF-alpha inducible protein 1

$\S$ TRAF4: TNF receptor associated factor 4

** TRAIL: TNF ligand family 10

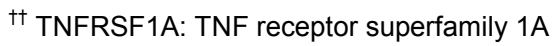

\# TGFBI68KD: TGF-beta induced 68KD

§§ IL10Ra: IL10 receptor alpha

*** CLF1: cytokine-like factor 1

${ }^{\dagger+\dagger}$ ADRM1:Adhesion-regulating molecule1 
Table 4. Lysosome-related gene expressions

\begin{tabular}{|c|c|c|c|c|c|c|c|c|c|c|c|c|c|}
\hline \multirow{4}{*}{ Gene } & \multirow{4}{*}{$\begin{array}{c}\text { GeneBank } \\
\text { Accession } \\
\text { Number }\end{array}$} & \multicolumn{12}{|c|}{ Fold change $^{*}$} \\
\hline & & \multicolumn{6}{|c|}{$6 \mathrm{~h}$} & \multicolumn{6}{|c|}{$24 \mathrm{~h}$} \\
\hline & & \multicolumn{4}{|c|}{ SARS-CoV } & \multicolumn{2}{|c|}{ CoV- 229E } & \multicolumn{4}{|c|}{ SARS-CoV } & \multicolumn{2}{|c|}{ CoV- 229E } \\
\hline & & Mean & A & $\mathrm{B}$ & Mean & A & $\mathrm{B}$ & Mean & $\mathrm{A}$ & $\mathrm{B}$ & Mean & A & $\mathrm{B}$ \\
\hline ATPaseV01 & NM005177 & 1.21 & 1.41 & 1.00 & 1.00 & 1.00 & 1.00 & 2.45 & 1.78 & 3.12 & 1.23 & 1.45 & 1.00 \\
\hline G-6-S $S^{\dagger}$ & NM002076 & 1.00 & 1.00 & 1.00 & 1.00 & 1.00 & 1.00 & 1.55 & 1.55 & 1.56 & 1.17 & 1.17 & 1.16 \\
\hline GlcNAcp $^{\ddagger}$ & NM032520 & $\underline{0.60}$ & 0.54 & 0.66 & 1.23 & 1.00 & 1.45 & $\underline{0.66}$ & 0.62 & 0.69 & 0.86 & 0.87 & 0.85 \\
\hline PPTE2 ${ }^{\S}$ & NM005155 & 0.75 & 0.69 & 0.81 & 1.00 & 1.00 & 1.00 & $\underline{0.66}$ & 0.57 & 0.75 & 1.02 & 1.02 & 1.03 \\
\hline Mannosidase & NM022077 & 0.80 & 0.81 & 0.78 & 0.80 & 0.73 & 0.87 & $\underline{0.66}$ & 0.48 & 0.85 & 0.84 & 0.86 & 0.82 \\
\hline ATPase14KDV1F & NM004231 & 0.87 & 0.86 & 0.88 & 0.72 & 0.81 & 0.63 & $\underline{0.67}$ & 0.40 & 0.97 & 0.93 & 0.96 & 0.90 \\
\hline ATPaseProtein1 & NM001183 & $\underline{0.62}$ & 0.63 & 0.62 & 0.99 & 1.00 & 0.97 & $\underline{0.60}$ & 0.57 & 0.62 & 0.81 & 0.84 & 0.78 \\
\hline LAMP4 alpha* & NM014713 & $\underline{0.56}$ & 0.50 & 0.62 & 0.89 & 1.33 & 0.46 & $\underline{0.59}$ & 0.59 & 0.59 & 1.03 & 1.09 & 0.97 \\
\hline PPTE $1^{\dagger \dagger}$ & NM000310 & 1.10 & 1.07 & 1.13 & 1.76 & 0.47 & 3.05 & $\underline{0.65}$ & 0.32 & 0.99 & 1.09 & 1.06 & 1.11 \\
\hline ATPase16KDV0C & NM001694 & 0.98 & 1.13 & 0.84 & 0.81 & 1.04 & 0.57 & $\underline{0.62}$ & 0.33 & 0.90 & 0.96 & 0.98 & 0.93 \\
\hline $\mathrm{AP} 2 \mathrm{M} 1^{\ddagger \ddagger}$ & $\underline{N M 004068}$ & 0.93 & 0.91 & 0.95 & 1.00 & 0.83 & 1.16 & $\underline{0.53}$ & 0.34 & 0.73 & 0.91 & 0.96 & 0.86 \\
\hline LAMP5 $5^{\S \S}$ & NM006762 & 1.16 & 1.13 & 1.19 & 0.92 & 0.92 & 0.91 & $\underline{0.52}$ & 0.23 & 0.81 & 1.02 & 1.01 & 1.02 \\
\hline ATPase21KDV0C & NM004047 & 1.01 & 1.02 & 0.99 & $\underline{0.67}$ & 0.85 & 0.49 & $\underline{0.46}$ & 0.29 & 0.64 & 0.76 & 0.79 & 0.73 \\
\hline Prosaposin & NM002778 & 0.72 & 0.74 & 0.70 & 1.34 & 1.52 & 1.17 & 0.49 & 0.22 & 0.75 & 1.00 & 0.97 & 1.03 \\
\hline
\end{tabular}

\footnotetext{
* Bold face=Up-regulation $>1.5 x$; Underlined boldface=down-regulation $<0.67 x$

${ }^{\dagger}$ G-6-S: glucosamine-6-sulfatase

‡ GlcNAcp:GlcNAc phosphotransferase

$\S$ PPTE2: palmitoyl-protein thioesterase2

** LAMP4 alpha: lysosomal-associated protein 4 alpha

${ }^{\dagger}$ PPTE1: palmitoyl-protein thioesterase1

执 AP2M1: adaptor-related protein complex 2, mu-1 subunit

$\S \S$ LAMP5: lysosomal-associated protein 5
} 
Table 5. Cathepsin/proteasome gene expressions

\begin{tabular}{|c|c|c|c|c|c|c|c|c|c|c|c|c|c|}
\hline \multirow{4}{*}{ Group/Gene } & \multirow{4}{*}{$\begin{array}{l}\text { GeneBank } \\
\text { Accession } \\
\text { Number }\end{array}$} & \multicolumn{11}{|c|}{ Fold change ${ }^{*}$} & \\
\hline & & \multicolumn{6}{|c|}{$6 \mathrm{~h}$} & \multicolumn{6}{|c|}{$24 \mathrm{~h}$} \\
\hline & & \multicolumn{4}{|c|}{ SARS-CoV } & \multicolumn{2}{|c|}{ CoV-229E } & \multicolumn{4}{|c|}{ SARS-CoV } & \multicolumn{2}{|c|}{ CoV-229E } \\
\hline & & Mean & $A$ & $\mathrm{~B}$ & Mean & $A$ & $\mathrm{~B}$ & Mean & A & B & Mean & A & $\mathrm{B}$ \\
\hline \multicolumn{14}{|l|}{ Cathepsins: } \\
\hline Cathepsin A & NM000308 & 0.87 & 0.75 & 0.99 & 1.22 & 1.00 & 1.43 & $\underline{0.59}$ & 0.40 & 0.78 & 0.88 & 0.92 & 0.84 \\
\hline Cathepsin S & NM004079 & $\underline{0.53}$ & 0.59 & 0.47 & 1.52 & 1.00 & 2.04 & $\underline{0.54}$ & 0.42 & 0.66 & 1.07 & 1.11 & 1.03 \\
\hline Cathepsin C & NM001814 & 1.14 & 0.90 & 1.39 & 1.17 & 0.66 & 1.67 & $\underline{0.53}$ & 0.42 & 0.63 & 0.95 & 0.95 & 0.96 \\
\hline Cathepsin $\mathrm{H}$ & NM004390 & $\underline{0.65}$ & 0.62 & 0.68 & 1.00 & 1.00 & 1.00 & $\underline{0.45}$ & 0.56 & 0.33 & 1.00 & 0.93 & 1.07 \\
\hline Cathepsin D & NM001909 & 1.09 & 0.90 & 1.28 & 0.75 & 1.00 & 0.49 & $\underline{0.39}$ & 0.24 & 0.54 & 1.29 & 1.34 & 1.25 \\
\hline \multicolumn{14}{|l|}{ Proteasomes: } \\
\hline Proteasome $\alpha 4$ (PSMA4) & NM002789 & 1.25 & 1.12 & 1.38 & 1.49 & 0.71 & 2.27 & $\underline{0.67}$ & 0.47 & 0.88 & 1.18 & 1.27 & 1.08 \\
\hline Proteasome $\beta 2$ (PSMB2) & NM002794 & 1.07 & 1.15 & 1.00 & 0.96 & 1.00 & 0.92 & $\underline{0.63}$ & 0.57 & 0.69 & 1.05 & 0.96 & 1.14 \\
\hline Proteasome $26 \mathrm{~s}, \mathrm{~A} 4^{\dagger}$ & NM006503 & 1.00 & 0.96 & 1.05 & 1.07 & 1.39 & 0.75 & $\underline{0.54}$ & 0.62 & 0.47 & 0.82 & 0.85 & 0.80 \\
\hline Proteasome $\beta 9$ (PSMB9) & NM002800 & $\underline{0.51}$ & 0.46 & 0.55 & 1.00 & 0.50 & 1.49 & $\underline{0.54}$ & 0.48 & 0.59 & 0.83 & 0.83 & 0.82 \\
\hline PSME2 $^{\ddagger}$ & BC072025 & 0.78 & 0.71 & 0.85 & 1.10 & 0.43 & 1.78 & $\underline{0.50}$ & 0.45 & 0.56 & 0.84 & 0.86 & 0.82 \\
\hline Proteassome $\beta 3$ (PSMB3) & NM002795 & 1.10 & 0.96 & 1.24 & 0.75 & 0.45 & 1.04 & $\underline{0.52}$ & 0.36 & 0.67 & 0.85 & 0.86 & 0.84 \\
\hline PSME $1^{\S}$ & NM006263 & 0.78 & 0.77 & 0.80 & 1.22 & 0.46 & 1.97 & $\underline{0.49}$ & 0.32 & 0.66 & 0.90 & 0.92 & 0.88 \\
\hline Proteasome $26 \mathrm{~s} n A 8$ & NM002812 & 1.20 & 1.06 & 1.33 & 0.96 & 0.70 & 1.21 & $\underline{0.46}$ & 0.36 & 0.55 & 0.85 & 0.84 & 0.86 \\
\hline Proteasome $\alpha 5$ (PSMA5) & NM002790 & 0.80 & 0.73 & 0.87 & 1.12 & 0.47 & 1.77 & $\underline{0.34}$ & 0.24 & 0.43 & 0.98 & 1.02 & 0.94 \\
\hline
\end{tabular}

\footnotetext{
* Bold face=Up-regulation $>1.5 x$; Underlined boldface=down-regulation $<0.67 x$

$\dagger$ Proteasome 26s, A4: proteasome 26s ATPase 4,

* PSME2: proteasome activator 2

$\S$ PSME1: proteasome activator 1
} 
Table 6. Chaperon/HLA gene expressions

\begin{tabular}{|c|c|c|c|c|c|c|c|c|c|c|c|c|c|}
\hline \multirow{4}{*}{ Gene } & \multirow{4}{*}{$\begin{array}{l}\text { GeneBank } \\
\text { Accession } \\
\text { Number }\end{array}$} & \multicolumn{12}{|c|}{ Fold change ${ }^{*}$} \\
\hline & & \multicolumn{6}{|c|}{$6 \mathrm{~h}$} & \multicolumn{6}{|c|}{$24 \mathrm{~h}$} \\
\hline & & \multicolumn{3}{|c|}{ SARS-CoV } & \multicolumn{3}{|c|}{ CoV- 229E } & \multicolumn{4}{|c|}{ SARS-CoV } & \multicolumn{2}{|c|}{ CoV-229E } \\
\hline & & Mean & A & $\mathrm{B}$ & Mean & A & $\mathrm{B}$ & Mean & $\mathrm{A}$ & $\mathrm{B}$ & Mean & $\mathrm{A}$ & $\mathrm{B}$ \\
\hline Cyclophilin D & NM005038 & 1.00 & 1.00 & 1.00 & 1.00 & 1.00 & 1.00 & 1.95 & 2.04 & 1.85 & 1.11 & 1.10 & 1.12 \\
\hline Heat Shock Factor 1 & $\underline{N M 005526}$ & 1.00 & 1.00 & 1.00 & 1.00 & 1.00 & 1.00 & 1.69 & 1.91 & 1.48 & 0.99 & 0.96 & 1.01 \\
\hline Cyclophilin G & NM004792 & 2.44 & 2.20 & 2.68 & 1.00 & 1.00 & 1.00 & 1.66 & 1.59 & 1.73 & 1.39 & 1.45 & 1.32 \\
\hline Chaperonin TCP16A & NM001762 & 1.36 & 1.78 & 0.95 & 1.28 & 1.93 & 0.63 & $\underline{0.63}$ & 0.64 & 0.62 & 1.15 & 1.04 & 1.27 \\
\hline HLA-B Associated 2 & NM004638 & 0.98 & 0.99 & 0.97 & 0.78 & 1.00 & 0.55 & $\underline{0.63}$ & 0.71 & 0.56 & 1.46 & 1.52 & 1.41 \\
\hline FK506BindingProtein8 & NM012181 & 0.69 & 0.58 & 0.81 & 0.85 & 0.65 & 1.05 & $\underline{0.64}$ & 0.51 & 0.76 & 0.87 & 0.91 & 0.84 \\
\hline Activator Of HSP90KD & NM012111 & 1.02 & 1.04 & 1.00 & 1.00 & 1.00 & 1.00 & $\underline{0.63}$ & 0.71 & 0.54 & 0.98 & 0.88 & 1.08 \\
\hline Cyclophilin E & NM006112 & 0.92 & 0.89 & 0.95 & 1.30 & 0.49 & 2.11 & $\underline{0.67}$ & 0.40 & 0.95 & 0.89 & 0.92 & 0.86 \\
\hline HLA-HA1 & NM012292 & 0.71 & 0.63 & 0.80 & 0.83 & 0.52 & 1.14 & $\underline{0.59}$ & 0.53 & 0.64 & 0.74 & 0.76 & 0.72 \\
\hline HLA complex group9 & $\underline{\text { NM005844 }}$ & 1.12 & 1.03 & 1.21 & 1.02 & 1.00 & 1.04 & $\underline{0.58}$ & 0.49 & 0.66 & 0.84 & 0.90 & 0.78 \\
\hline BAP31 $^{\dagger}$ & $\underline{\text { NM005745 }}$ & 0.74 & 0.71 & 0.77 & 0.98 & 0.59 & 1.37 & $\underline{0.60}$ & 0.41 & 0.78 & 0.93 & 0.95 & 0.92 \\
\hline SEC61 complex Beta & NM006808 & 0.80 & 0.73 & 0.88 & $\underline{0.62}$ & 0.74 & 0.51 & $\underline{0.61}$ & 0.38 & 0.84 & 0.87 & 0.93 & 0.80 \\
\hline Cyclophilin C & NM000943 & $\underline{0.58}$ & 0.57 & 0.59 & 1.07 & 0.57 & 1.57 & $\underline{0.62}$ & 0.32 & 0.92 & 0.91 & 0.91 & 0.91 \\
\hline Valosin-contain protein & $\underline{\text { NM007126 }}$ & 1.18 & 1.25 & 1.11 & 1.06 & 1.09 & 1.02 & $\underline{0.53}$ & 0.36 & 0.71 & 0.93 & 0.90 & 0.95 \\
\hline HeatShockProtein10KD & 1 NM002157 & 0.86 & 0.84 & 0.88 & 1.25 & 0.37 & 2.13 & $\underline{0.51}$ & 0.37 & 0.66 & 0.87 & 0.88 & 0.87 \\
\hline Chaperonin TCP1-7 & $\underline{\text { NM006429 }}$ & 2.20 & 1.78 & 2.62 & 0.89 & 0.49 & 1.29 & $\underline{0.49}$ & 0.37 & 0.61 & 0.98 & 0.97 & 0.99 \\
\hline X-box binding protein1 & NM005080 & $\underline{0.41}$ & 0.42 & 0.41 & 1.59 & 0.40 & 2.77 & $\underline{0.49}$ & 0.36 & 0.62 & 1.08 & 1.14 & 1.03 \\
\hline FK506BindingProtein 10 & NM021939 & $\underline{0.66}$ & 0.68 & 0.63 & 1.03 & 1.23 & 0.83 & $\underline{0.48}$ & 0.36 & 0.61 & 0.89 & 0.88 & 0.91 \\
\hline HeatShockProtein70KDE & 8 NM006597 & 1.02 & 1.09 & 0.95 & 1.80 & 0.54 & 3.05 & $\underline{0.46}$ & 0.27 & 0.65 & 1.52 & 1.56 & 1.48 \\
\hline Calreticulin & $\underline{N M 004343}$ & 1.23 & 1.36 & 1.10 & 1.96 & 2.45 & 1.48 & $\underline{0.43}$ & 0.23 & 0.62 & 1.27 & 1.23 & 1.31 \\
\hline Cyclophilin B & NM000942 & 0.69 & 0.71 & 0.67 & 1.12 & 0.54 & 1.71 & $\underline{0.36}$ & 0.12 & 0.59 & 1.03 & 1.04 & 1.01 \\
\hline
\end{tabular}

\footnotetext{
* Bold face=Up-regulation $>1.5 \mathrm{x}$; Underlined boldface=down-regulation $<0.67 \mathrm{x}$

† BAP31: B cell receptor associated protein 31
} 
Table 7. Chemokine-related gene expressions

\begin{tabular}{|c|c|c|c|c|c|c|c|c|c|c|c|c|c|}
\hline \multirow{4}{*}{ Gene } & \multicolumn{13}{|c|}{ Fold change ${ }^{*}$} \\
\hline & \multirow{3}{*}{$\begin{array}{c}\text { GeneBank } \\
\text { Accession } \\
\text { Number }\end{array}$} & \multicolumn{6}{|c|}{$6 \mathrm{~h}$} & \multicolumn{6}{|c|}{$24 \mathrm{~h}$} \\
\hline & & \multicolumn{4}{|c|}{ SARS -CoV } & \multicolumn{2}{|c|}{ CoV-229E } & \multicolumn{4}{|c|}{ SARS- CoV } & \multicolumn{2}{|c|}{ CoV-229E } \\
\hline & & Mean & A & B & Mean & A & $\mathrm{B}$ & Mean & A & $\mathrm{B}$ & Mean & A & $\mathrm{B}$ \\
\hline $\mathrm{MBPH}(\mathrm{PRG} 3)^{\dagger}$ & $\underline{\text { NM006093 }}$ & 1.74 & 1.74 & 1.74 & 1.09 & 1.84 & 0.33 & 2.57 & 2.83 & 2.31 & 1.05 & 1.15 & 0.96 \\
\hline Interleukin8 & NM000584 & 0.80 & 0.60 & 1.00 & 8.50 & 16.91 & 0.08 & 2.55 & 2.28 & 2.83 & 0.91 & 0.90 & 0.92 \\
\hline C/EBP delta(CEBPD) & $\underline{\text { NM005195 }}$ & 1.18 & 1.05 & 1.32 & 0.82 & 1.21 & 0.44 & 2.04 & 1.30 & 2.77 & 0.86 & 0.79 & 0.82 \\
\hline Hyaluronidase 3 & $\underline{\text { NM003549 }}$ & 1.29 & 1.27 & 1.30 & 1.00 & 1.00 & 1.00 & 1.80 & 1.35 & 2.25 & 0.79 & 0.77 & 0.81 \\
\hline Complement3 & NM000064 & 1.09 & 1.18 & 1.00 & 1.00 & 1.00 & 1.00 & 1.66 & 1.75 & 1.57 & 0.99 & 0.93 & 1.05 \\
\hline PDGF receptor alpha & NM006206 & 1.03 & 1.00 & 1.06 & 1.00 & 1.00 & 1.00 & 1.65 & 1.68 & 1.62 & 1.27 & 1.29 & 1.24 \\
\hline LTXA4 hydroxylase ${ }^{\ddagger}$ & $\underline{\text { NM000895 }}$ & 1.00 & 1.00 & 1.00 & 1.00 & 1.00 & 1.00 & 1.68 & 1.37 & 1.99 & 1.08 & 1.07 & 1.08 \\
\hline CD14 & NM000591 & 1.00 & 1.00 & 1.00 & 1.00 & 1.00 & 1.00 & 1.58 & 1.62 & 1.54 & 1.14 & 1.24 & 1.04 \\
\hline $\mathrm{RHMM}^{\S}$ & NM012484 & 1.64 & 2.28 & 1.00 & 1.00 & 1.00 & 1.00 & 1.55 & 1.71 & 1.40 & 1.40 & 1.34 & 1.46 \\
\hline MGST2 $^{* *}$ & NM002413 & $\underline{0.55}$ & 0.54 & 0.57 & 1.21 & 0.43 & 2.00 & $\underline{0.59}$ & 0.50 & 0.69 & 0.95 & 0.96 & 0.93 \\
\hline PGE Synthase & NM004878 & 1.10 & 0.86 & 1.34 & 1.00 & 1.00 & 1.00 & $\underline{0.58}$ & 0.59 & 0.57 & 1.15 & 1.18 & 1.13 \\
\hline $\mathrm{CLF}^{\dagger \dagger}$ & NM016326 & 0.83 & 0.65 & 1.00 & 1.00 & 1.00 & 1.00 & $\underline{0.58}$ & 0.72 & 0.44 & 1.16 & 1.25 & 1.08 \\
\hline CXCL3 & $\underline{\text { NM002090 }}$ & 0.77 & 0.74 & 0.81 & 0.97 & 1.39 & 0.55 & $\underline{0.56}$ & 0.41 & 0.70 & 0.82 & 0.85 & 0.78 \\
\hline ANPEP ${ }^{\ddagger \ddagger}$ & NM001150 & 0.75 & 0.78 & 0.71 & 0.85 & 1 & 0.69 & $\underline{0.57}$ & 0.47 & 0.68 & 1.08 & 1.13 & 1.04 \\
\hline MGST ${ }^{\S \S}$ & $\underline{\text { NM004528 }}$ & 0.76 & 0.73 & 0.78 & 0.92 & 0.35 & 1.48 & $\underline{0.57}$ & 0.36 & 0.78 & 0.89 & 0.87 & 0.91 \\
\hline CCL3 & NM002983 & 0.19 & 0.20 & 0.18 & 1.35 & 1.00 & 1.69 & $\underline{0.49}$ & 0.52 & 0.45 & $\underline{0.39}$ & 0.42 & 0.37 \\
\hline PGD Synthase & NM014485 & 0.49 & 0.44 & 0.55 & 0.98 & 1.00 & 0.95 & $\underline{0.54}$ & 0.28 & 0.80 & 0.82 & 0.85 & 0.78 \\
\hline CCR9 & NM006641 & 0.95 & 1.07 & 0.84 & 1.47 & 2.17 & 0.76 & $\underline{0.47}$ & 0.37 & 0.57 & 0.93 & 0.93 & 0.92 \\
\hline CCL5 & NM002985 & 0.35 & 0.33 & 0.38 & 0.73 & 0.87 & 0.59 & $\underline{0.28}$ & 0.26 & 0.29 & 0.94 & 1.02 & 0.86 \\
\hline LeukotrieneC4synthase & NM000897 & 0.32 & 0.28 & 0.37 & 1.30 & 1.00 & 1.59 & $\underline{0.28}$ & 0.25 & 0.30 & 0.69 & 0.74 & 0.64 \\
\hline
\end{tabular}

* Bold face=Up-regulation $>1.5 \mathrm{x}$; Underlined boldface=down-regulation $<0.67 \mathrm{x}$

${ }^{\dagger} \mathrm{MBPH}$ : Major basic protein homolog

${ }^{\ddagger}$ LTXA4 hydroxylase: leukotriene A4 hydroxylase

$\S$ RHMM: hyaluronan-mediated motility receptor

** MGST2: microsomal glutathione-S-transfersae2

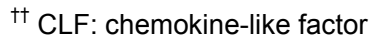

¥¥ ANPEP:alanyl aminopeptidase

$\S$ MGST3: microsomal glutathione-S-transfersae2 
Table 8. Fibrosis-related gene expressions

\begin{tabular}{|c|c|c|c|c|c|c|c|c|c|c|c|c|c|}
\hline \multirow{4}{*}{ Gene } & \multicolumn{13}{|c|}{ Fold change $^{*}$} \\
\hline & \multirow{3}{*}{$\begin{array}{c}\text { GeneBank } \\
\text { Accession } \\
\text { Number }\end{array}$} & \multicolumn{6}{|c|}{$6 \mathrm{~h}$} & \multicolumn{6}{|c|}{$24 \mathrm{~h}$} \\
\hline & & \multicolumn{4}{|c|}{ SARS -CoV } & \multicolumn{2}{|c|}{ CoV-229E } & \multicolumn{4}{|c|}{ SARS-CoV } & \multicolumn{2}{|c|}{ CoV-229E } \\
\hline & & Mean & A & $\mathrm{B}$ & Mean & A & $\mathrm{B}$ & Mean & A & $\mathrm{B}$ & Mean & A & $\mathrm{B}$ \\
\hline $\mathrm{P} \mathrm{HA} 1^{\dagger}$ & NM000917 & 2.12 & 3.25 & 1.00 & 2.07 & 3.81 & 0.33 & 2.93 & 1.69 & 4.17 & 1.17 & 1.13 & 1.21 \\
\hline SERPINB2 ${ }^{\ddagger}$ & NM002575 & 1.12 & 1.25 & 1.00 & 1.00 & 1.00 & 1.00 & 2.69 & 1.29 & 4.08 & 1.08 & 1.02 & 1.13 \\
\hline MMP28 $8^{\S}$ & NM024302 & 1.00 & 1.00 & 1.00 & 1.00 & 1.00 & 1.00 & 1.75 & 1.99 & 1.51 & 0.77 & 0.77 & 0.78 \\
\hline ADAM19 ${ }^{* *}$ & NM023038 & 1.00 & 1.00 & 1.00 & 1.00 & 1.00 & 1.00 & 1.65 & 1.62 & 1.67 & 1.07 & 1.13 & 1.01 \\
\hline Protein S & $\underline{\text { NM000313 }}$ & 0.58 & 0.62 & 0.55 & 1.00 & 1.00 & 1.00 & $\underline{0.66}$ & 0.60 & 0.71 & 1.24 & 1.26 & 1.23 \\
\hline $\mathrm{MMP}^{\dagger \dagger}$ & NM004530 & 0.94 & 0.88 & 1.00 & 1.00 & 1.00 & 1.00 & $\underline{0.64}$ & 0.55 & 0.74 & 0.91 & 0.88 & 0.94 \\
\hline Spondin2 & NM012445 & 0.82 & 0.84 & 0.79 & 1.04 & 0.70 & 1.38 & $\underline{0.63}$ & 0.43 & 0.82 & 0.93 & 0.94 & 0.93 \\
\hline PLOD $3^{\ddagger \ddagger}$ & NM001084 & 0.73 & 0.64 & 0.81 & 1.07 & 0.68 & 1.46 & $\underline{0.61}$ & 0.78 & 0.44 & 0.71 & 0.74 & 0.67 \\
\hline ADAMTS $4^{\S \S}$ & NM005099 & 0.80 & 0.59 & 1.00 & 1.00 & 1.00 & 1.00 & $\underline{0.56}$ & 0.62 & 0.50 & 1.10 & 1.19 & 1.01 \\
\hline $\mathrm{FGF}^{* * *}$ & NM005247 & 0.92 & 0.83 & 1.01 & 0.97 & 0.69 & 1.24 & $\underline{0.50}$ & 0.29 & 0.73 & 1.01 & 1.01 & 1.02 \\
\hline CollagenXVIIIa1 & NM030582 & 0.76 & 0.75 & 0.77 & 0.81 & 0.89 & 0.74 & $\underline{0.48}$ & 0.31 & 0.66 & 0.90 & 0.93 & 0.87 \\
\hline $\mathrm{TIMP}{ }^{t+\dagger}$ & NM000362 & 1.03 & 0.93 & 1.13 & 1.16 & 1.26 & 1.06 & $\underline{0.45}$ & 0.26 & 0.63 & 1.09 & 1.13 & 1.06 \\
\hline Collagenla2 & NM000089 & 0.57 & 0.57 & 0.57 & 0.98 & 0.91 & 1.04 & $\underline{0.40}$ & 0.25 & 0.55 & 0.97 & 0.93 & 1.01 \\
\hline TIMP $1^{\text {拉 }}$ & NM003254 & 0.75 & 0.69 & 0.81 & $\underline{0.67}$ & 0.82 & 0.51 & $\underline{0.38}$ & 0.15 & 0.62 & 0.98 & 1.04 & 0.91 \\
\hline
\end{tabular}

\footnotetext{
* Bold face=Up-regulation $>1.5 x$; Underlined boldface=down-regulation $<0.67 x$

${ }^{\dagger} \mathrm{P} 4 \mathrm{HA} 1$ : proline 2-oxoglutarate 4-dioxygenase

‡ SERPINB2: plasminogen activator inhibitor type 2

${ }^{\S}$ MMP28: matrix metalloproteinase 28

** ADAM19: A disintegrin and metalloproteinase 19

† MMP2: matrix metalloproteinase 2

\# PLOD3: procollagenlysine-2-oxoglutarate-5-dioxygenase 3

$\S$ ADAMTS4: ADAM metalloproteinase with thrombospondin type 1 motif 4

${ }^{* * *}$ FGF3: fibroblast growth factor 3

${ }^{\mathrm{tt \dagger}}$ TIMP3: tissue inhibitor of metalloproteinase 3

\#¥ TIMP1: tissue inhibitor of metalloproteinase 1
} 
Table 9. Hypoxia-related gene expressions

\begin{tabular}{|c|c|c|c|c|c|c|c|c|c|c|c|c|c|}
\hline \multirow{4}{*}{ Gene } & \multirow{4}{*}{$\begin{array}{l}\text { GeneBank } \\
\text { Accession } \\
\text { Number }\end{array}$} & \multicolumn{12}{|c|}{ Fold change $^{*}$} \\
\hline & & \multicolumn{6}{|c|}{$6 \mathrm{~h}$} & \multicolumn{6}{|c|}{$24 \mathrm{~h}$} \\
\hline & & \multicolumn{4}{|c|}{ SARS -CoV } & \multicolumn{2}{|c|}{ CoV-229E } & \multicolumn{4}{|c|}{ SARS-CoV } & \multicolumn{2}{|c|}{ CoV-229E } \\
\hline & & Mean & $\mathrm{A}$ & $\mathrm{B}$ & Mean & A & $\mathrm{B}$ & Mean & A & B & Mean & A & $\mathrm{B}$ \\
\hline Hypoxia-inducible2 & NM013332 & 1.44 & 1.41 & 1.47 & 1.11 & 1.91 & 0.31 & 1.92 & 1.17 & 2.66 & 1.11 & 1.11 & 1.11 \\
\hline Oxidative responsive1 & NM005109 & 1.00 & 1.00 & 1.00 & 0.87 & 1.00 & 0.73 & 1.64 & 1.83 & 1.45 & 1.04 & 0.97 & 1.12 \\
\hline Hypoxia up-regulated 1 & NM006389 & 1.52 & 1.49 & 1.55 & 0.78 & 0.90 & 0.67 & 1.65 & 1.29 & 2.01 & 0.99 & 1.09 & 0.88 \\
\hline
\end{tabular}

${ }^{*}$ Bold face=Up-regulation $>1.5 x$; Underlined boldface=down-regulation $<0.67 x$ 
Figure 1

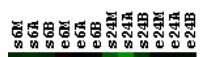

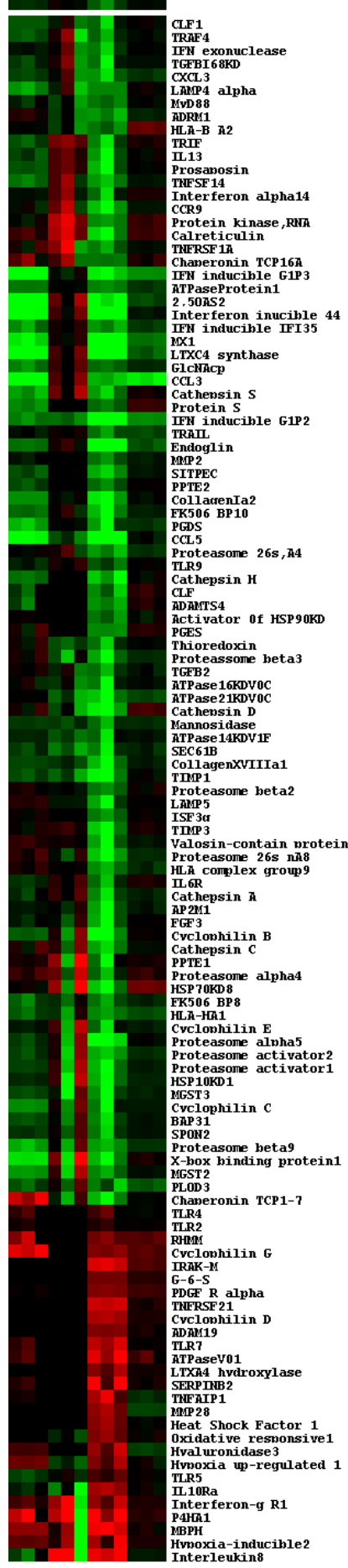




\section{Figure 2}

Network 1: 102207SARSgene - 2007-10-23 03:10 घu: 102207SARSgene.txt

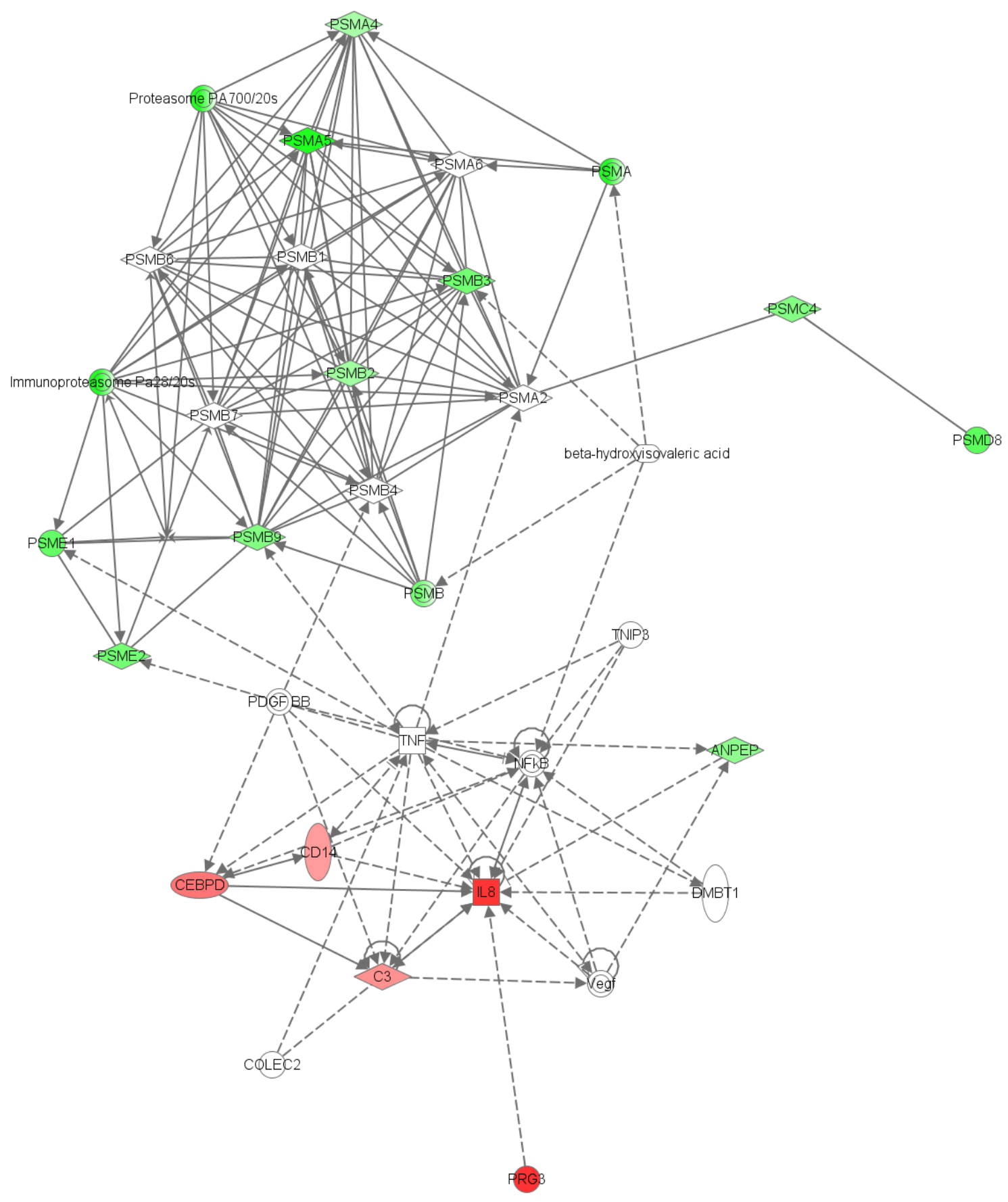

๑9 2000-2007 Ingenuity Systems, Inc. All rights reserved. 